\title{
Olfactory imagery: A review
}

\author{
RICHARD J. STEVENSON and TREVOR I. CASE \\ Macquarie University, Sydney, New South Wales, Australia
}

\begin{abstract}
Olfaction's unique cognitive architecture, the apparently inconsistent evidence favoring imagery, and its difficulty of evocation have led some to conclude that there is no capacity for olfactory imagery. Using three streams of evidence, we examine the validity of this claim. First, self-reports of olfactory imagery can resemble those obtained for actual perception. Second, imagining an odor can produce effects similar to actual perception. Third, olfactory perception and memory-based images can interact. A model of olfactory imagery is then presented that utilizes the same systems employed in actual perception, with similar constraints. This model is consistent with olfaction's unique information-processing capacities and can account for previous experimental inconsistencies on the basis of difficulty of evocation, a consequence of unstable access to semantic information. In sum, the evidence presented here is favorable to the existence of an olfactory imagery capacity.
\end{abstract}

When a participant forms a visual image, the process is likely to involve three key elements: (1) the retrieval of an encoding from long-term memory, (2) its instantiation in a short-term visual store, and (3) a perceptual form of representation (Baddeley \& Andrade, 2000; Kosslyn, Ganis, \& Thompson, 2003; Kosslyn \& Thompson, 2003). It would be reasonable to assume that forming an olfactory image would be similar, if not for the fact that the three key elements outlined above may take rather different forms in this modality. Whereas normal participants have little difficulty naming familiar objects presented visually, identification performance is very poor when the same objects are smelled (Cain, 1979). To the extent that retrieval is reliant upon connections reciprocal to those involved in generating a name, it may also be hard for participants to retrieve an olfactory encoding from long-term memory - an image (Engen, 1991). Notwithstanding this potential difficulty, evidence favoring a dissociable short-term store in olfaction is equivocal (T. L. White, 1998). There are no neuropsychological findings indicative of long- and short-term stores and no consistent coding differences between tasks presumed to access each type of store, and capacity difference experiments are open to alternative interpretations (Stevenson $\&$ Boakes, 2003). Finally, there is considerable debate over the degree to which olfactory cognition is semantically or perceptually mediated (see Cain, de Wijk, Lulejian, Schiet, \& See, 1998), since some researchers view olfactory cognition as primarily a semantic process (e.g., Lorig, 1999). Perhaps not surprisingly, in light of the information above, the very claim that we can experience olfactory imagery is itself a matter of some controversy.

Thanks to Bob Boakes and Julie Fitness for commenting on earlier versions of this article and to its three reviewers, whose comments were invaluable. Correspondence relating to this article may be sent to R. J. Stevenson, Department of Psychology, Macquarie University, Sydney, NSW 2109, Australia (e-mail: rstevens@psy.mq.edu.au).
Several leading authorities on olfaction claim that olfactory imagery does not occur (e.g., Crowder \& Schab, 1995; Engen, 1991; Herz, 2000), whereas others of equal stature argue that it does (e.g., Cain \& Algom, 1997; Elmes, 1998). Consequently, a review of the olfactory imagery literature appears timely, in order to establish whether there is solid evidence favoring olfactory imagery; to delineate what further evidence may be required; and to identify how the olfactory system might go about forming images and how this process may occur differently for the olfactory system than for other modalities.

An important consideration before starting this review is to determine its scope. Several factors are important here, but the most crucial concerns our definition of imagery. The definition we employ is that of being able to experience the sensation of smell when an appropriate stimulus is absent. Evidence pertinent to this definition can only be examined directly using self-report data, with all its attendant shortcomings. Three forms of evidence are available: (1) participants report such experiences; (2) their descriptions of these experiences are similar to those of actual smelling; and (3) their reactions to certain forms of these experiences involve appropriate behavioral responses. Each of these types of evidence is examined in the first section of the review, under the rubric "phenomenal imagery."

A less direct approach to imagery has been to study whether the process of imagining an odor results in task performance akin to that generated by its real olfactory equivalent. In this case, the definition of imagery above becomes one of a number of competing explanations of any performance similarity. For example, it is plausible that being asked to imagine an odor might produce no phenomenal experience, but still generate similar performance to real smelling. Consequently, we refer to this body of findings as "performance imagery" to emphasize its difference from phenomenal imagery. A related issue is to identify what actually may cause any perfor- 
mance similarity. One approach is to examine whether phenomenal imagery is related to performance imagery. Another is to examine whether performance similarities rely upon nonimaginal processes, such as semantic mediation. Evidence relevant to these questions, and to the performance imagery literature in general, is examined in the second section of the review.

Performance imagery studies generally ask participants to evoke an image. However, there are a variety of experimental tasks in which images may play a role but in which no explicit instruction is ever given to form one. For example, white wine colored red may be judged to have similar olfactory properties to red wine when participants can see the stimulus but not when judged blind (Morrot, Brochet, \& Dubourdieu, 2001). To the extent that one percept is wholly stimulus driven (e.g., white wine perceived as white wine), the percept generated under subsequent conditions can be viewed as an amalgam of the stimulus-driven percept and an automatically evoked, color-cued, memory-based image. Evidence for such "cued images" and whether they too rely primarily upon a perceptual or a semantic code is examined in the third section of the review.

Cued images raise a further definitional issue that influences the scope of this review-volition. Because of the relative scarcity of data on odor imagery, the review draws upon all available sources, both volitional and nonvolitional. Examples of the latter sources include olfactory hallucinations and dreams. There are fairly good grounds for including these nonvolitional sources, apart from pragmatic considerations, as several authors have suggested a gradation of mental experience from perception to thought, encompassing dreams, imagery, and hallucinations in between (e.g., Barodawala \& Mulley, 1997; Barrett \& Caylor, 1998; Fischman, 1983; Horowitz, 1975). Moreover, others have suggested that many of these phenomena share common mechanisms with perception (e.g., Andrade, Srinath, \& Andrade, 1989; Finke, 1980, 1985; Kerr, 1993; Smith, 1992; Weiss \& Heckers, 1999).

A final note is required in order to emphasize the distinction between the sense of taste and that of smell. Typically, a smell is thought of as the consequence of sniffing an odorous object. However, this conceptualization ignores two of the major sources of olfactory experience-eating and drinking. Eating and drinking primarily involve the integration of at least two separate sensory systems, taste and smell (Lawless, 1996). Taste is a relatively simple system that is composed of few qualitative dimensions (sweet, sour, salty, bitter, umami) and results from the detection of chemicals by receptors on the surface of the tongue (McLaughlin \& Margolskee, 1994). The olfactory component of eating and drinking occurs through the diffusion of volatiles via the nasopharynx to the olfactory receptors - the same receptors that are stimulated when an odorous object is sniffed (Pierce $\&$ Halpern, 1996). The distinction between taste and smell is an important one for two reasons: First, many participants regard eating and drinking as involving only taste stimuli and do not understand the role of smell. This perception has been exploited in some imagery experiments. Second, several of the studies described below involve both taste and smell, so it is important to bear in mind that these are separate sensory systems.

\section{SECTION 1: PHENOMENAL IMAGERY}

In this section, reports of olfactory experience in the absence of appropriate stimulation are examined, organized by the condition, state, or manipulation claimed to produce them. In each case, we consider (1) correspondences with actual perception, (2) prevalence, (3) vividness, and (4) whether other explanations might better account for the observed report. In terms of correspondences between phenomenal imagery and real smelling, three characteristics are of particular interest: First, is the experience reported to be emotive? Emotional reactions to odors are a primary component of actual olfactory experience (Rouby \& Bensafi, 2002) and are of greater intensity than those evoked by visual stimuli (Hinton \& Henley, 1993). Second, what is the experience redolent of? The qualities of odors (e.g., the degree to which they smell like cherry, etc.) typically cover a broad range (Lawless, 1997). Third, how long did it last? Olfactory experience may be brief, due to central/peripheral adaptation (Engen, 1982). Finally, as the types of information described above are useful for determining similarities between phenomenal and real olfactory experiences, reports that identify that an image occurred but that do not have any accompanying detail are not included here. Such experiences include hypnotically induced olfactory images (Fisher, 1955) and reports of hallucinations in Parkinson's (Sandyk, 1981) and Alzheimer's (Devanand et al., 1992) diseases.

\section{Olfactory Hallucinations}

Schizophrenia. Prevalence estimates of olfactory hallucinations (OHs) in schizophrenia vary from $2 \%$ to 35\% (Bowman \& Raymond, 1931; Kopala, Good, \& Honer, 1994; Mueser, Bellack, \& Brady, 1990; Stedman $\&$ Clair, 1998). Schizophrenic OHs have one major theme: They are very emotive, and typically foul smelling (e.g., Bullen, 1899; Davidson, 1938; Pryse-Phillips, 1975; Seydell, 1932). The perceptual quality of the experience can either be vague or redolent of malodors such as gas, body odor, or burning hair. Reports of hedonically positive OHs are rarer and include hay (Bromberg \& Schilder, 1934) and pine cones (Rubert, Hollender, \& Mehrhof, 1961). The temporal characteristics of OHs are not well documented. Bullen reported that OHs come in discrete "gusts," and others have suggested that OHs may persist for hours (Bromberg \& Schilder, 1934). Both Bullen (1899) and Bromberg and Schilder (1934) have noted that the same $\mathrm{OH}$ may be experienced repeatedly.

The majority of studies have also suggested that $\mathrm{OHs}$ are usually attributed to an environmental source (Brom- 
berg \& Schilder, 1934; Bullen, 1899; Pryse-Phillips, 1971, 1975). This idea led Bromberg and Schilder to remark that "there is no difference in quality between $\mathrm{OHs}$ and actual smells" (p. 488). Although this claim may have some merit, there are two reasons to query it. First, some OHs are simply bizarre (e.g., devil's breath, space aliens, holiness, or angel smell) and may be better characterized as delusions rather than hallucinations (Greenberg, 1995). Second, although there are some recorded instances in which people have reacted to $\mathrm{OHs}$ as if they were real, such as by attempting to lead people out of a building that "smelled" of smoke (Rubert et al., 1961), reactions in the main tend to be passive (Pryse-Phillips, 1971). This may be a consequence of symptom "relativity," as auditory hallucinations, which often co-occur with OHs (Rubert et al., 1961), are generally far more distressing and clearly can precipitate behavior.

OHs in schizophrenia do not appear to result from a proximal cause, such as damage to the sinuses or olfactory mucosa, or from deficits in odor identification. Kerekovic (1972) examined 40 schizophrenics who reported OHs for nasal pathology. Although nasal pathology was present in 13 of these patients, possibly accounting for some of their experiences, the other 27 evidenced no nasal pathology but still reported OHs. In a similar vein, no biochemical abnormalities in olfactory mucosa of schizophrenics have so far been detected (Smutzer, Trojanowski, Lee, \& Arnold, 1998). Misidentification also appears an unlikely explanation (e.g., confusing cooking smells with rotting fish). Kopala et al. (1994) found no evidence of a relationship between score on the University of Pennsylvania Smell Identification Test (UPSIT), a standardized test of odor naming, and presence or absence of OHs in 131 schizophrenic participants.

Posttraumatic stress disorder. Burstein (1987) described two cases involving gasoline and smoke OHs, both directly related to earlier traumatic experiences. In one case, the $\mathrm{OH}$ was so convincing (smelling petrol in a car) that verification from another person was sought. A further case was described by Ellenson (1986) of an incest survivor who experienced an $\mathrm{OH}$ of body odor accompanied by related hallucinations of someone attempting to abuse her. In both of these cases, there was no obvious proximal cause for the $\mathrm{OH}$.

Cerebral aneurysm. Mizobuchi et al. (1999) described an individual with an aneurysm in the anterior insular cortex that also affected the right orbitofrontal cortex (secondary olfactory cortex). This individual experienced pleasant, frequent, and brief $\mathrm{OHs}$, redolent of flowers or sweet fruits. Toone (1978) reported a person with an arteriovenous malformation in the right frontal lobe. He experienced a variety of $\mathrm{OHs}$, both positive and negative. The most dramatic $\mathrm{OH}$ he reported occurred when he entered a bar and complimented the proprietor on the delicious roast lunch he could smell cooking. He was informed that there was no such smell and that no lunches were being prepared. A third case was described by Whittle, Allsop, and Halmagyi (1985), in which pleasant, brief, floral OHs followed an aneurysm of the middle cerebral artery.

Epilepsy. Prevalence estimates of OHs associated with epilepsy vary considerably, from $1 \%$ to $30 \%$ (Allen, 1944; Lennox \& Cobb, 1935; West \& Doty, 1995). OHs prior to seizure are generally described as being unpleasant and are qualitatively similar to those in schizophrenia (e.g., Hamilton, 1882; Hausser-Hauw \& Bancaud, 1987; Jackson \& Beevor, 1890; Mulder \& Daly, 1952; Potolicchio, Lossing, O’Doherty, \& Henkin, 1986; Rosman, 1974; Wells, 1971). Pleasant OHs are also reported and include camphor (Jackson \& Stewart, 1899), barbecue, alcohol, toothpaste, peanut butter, floral (Acharya, Acharya, \& Luders, 1998), peach (Daly, 1958), sweet, perfume (Stevens, 1957), and pineapple (Chitanondh, 1966) odors. Epileptic OHs are usually brief (lasting seconds or minutes), precede the seizure (Acharya et al., 1998), and can be repetitive (e.g., Daly, 1958; Weil, 1955).

In epilepsy, there are several examples of appropriate behavior triggered by the $\mathrm{OH}$. Efron (1956) described a woman who experienced a "vague smell" that she attributed to the flowers she was picking. She asked her friend if she too could smell the flowers, as well as repeatedly trying to smell them again. The flowers in fact had no odor. Similarly, Daly (1958) described two cases, one of whom initially tried to open a window when she perceived a foul smell, and another who asked her friend if she could smell an overpowering peach odor. More strikingly, Embril, Camfield, Artsob, and Chase (1983) and Scully, Galdabini, and McNeely (1979) both reported cases in which the $\mathrm{OH}$ was so disgusting (rotting fish) that an extensive search ensued to try to locate its source.

Nasal pathology and impoverished odor identification in epilepsy (Eskenazi, Cain, Novelly, \& Friend, 1983) might explain the presence of certain OHs. Although studies relating odor identification to $\mathrm{OHs}$ have not been conducted, in one report, a study of a single case, an epileptic with OHs was examined for nasal pathology, but the authors found no evidence for it (Devinsky, Khan, \& Alper, 1998).

Migraine. OHs have also been documented prior to migraine. Of the nine cases reported in depth in the literature, six reported unpleasant odors (Ardila \& Sanchez, 1988; Crosley \& Dhamoon, 1983; Fuller \& Guiloff, 1987; Wolberg \& Ziegler, 1982). In at least two cases, the OHs were explicitly described as being repetitive (Diamond, Freitag, Prager, \& Gandi, 1985; Wolberg \& Ziegler, 1982). The duration of the OHs varied from 5 min to 2 hours (Fuller \& Guiloff, 1987; Wolberg \& Ziegler, 1982). In all cases, the $\mathrm{OH}$ was attributed to an environmental cause, a point well made by Crosley and Dhamoon's patient, whose home was repeatedly investigated for "gas leaks." As to the cause of the OHs, in four cases more extensive physical investigations with EEG, olfactory tests, and brain imaging ruled out epilepsy or nasal pathology (Fuller \& Guiloff, 1987; Wolberg \& Ziegler, 1982). 
Drug abuse. OHs have been reported in cocaine abusers and in chronic alcoholics. Siegel (1978), in a study of 85 recreational cocaine users, found 6 who reported OHs. All of the OHs were unpleasant odors and were initially treated as real, as validation was sought from other people. In terms of cause, 3 of the participants had rhinitis and 1 had damage to the nasal septum, so some of these OHs may have had a peripheral rather than a central cause. Bromberg and Schilder (1934) documented 11 cases of OHs following acute alcohol withdrawal. In all 11, the OHs were reported as unpleasant. Bromberg and Schilder drew no distinction between the nature of the $\mathrm{OHs}$ in these cases and those observed in their companion sample of schizophrenics, as both the qualities of the $\mathrm{OHs}$ and their external attribution were indistinguishable. Likewise, Kerekovic (1972) reported 20 cases of $\mathrm{OH}$ in a sample of 184 chronic alcoholics. These were again typified by unpleasant $\mathrm{OHs}(80 \%)$. Importantly, this study found no nasal pathology in the alcoholics who had experienced OHs.

Brain injury of various etiologies. Faris and Terrence (1989) described the case of a man with repeated $\mathrm{OHs}$, often redolent of diesel fuel, for whom each attack lasted 2-3 days. Neurological examination indicated a cyst in the third ventricle, which was probably pressing upon the dorsomedial nucleus of the thalamus, a structure known to be involved in olfactory perception. In another case, Kaufman, Lassiter, and Shenoy (1988) described a woman who had experienced unpleasant OHs for several years following a mild head injury. These OHs varied in length from seconds to hours, and on some occasions were so repellant that she vomited. The $\mathrm{OH}$ could be initiated by striking the left nostril, shaking her head, or by stress. No abnormalities of smell or taste perception were detected, nor of the sinuses. Finally, Chitanondh (1966) described a similar case of a man who had experienced OHs since having a car accident. These included smelling a "bad odor" for an hour or so after waking and briefly experiencing pleasant (flowers) or unpleasant (smoke) OHs. Chitanondh observed that the person was anosmic on one side and hyposmic on the other.

Miscellaneous physical causes. A brief report of three OHs induced by cancer chemotherapy was described by Nesse, Carli, Curtis, and Kleinman (1983). In each case, thinking about the cancer clinic or seeing it induced an $\mathrm{OH}$ of either the clinic's smell or the smell of the medication. In one case, the person asked her husband if he could smell the chemical odor that she vividly perceived. Another condition in which hallucinations are common, albeit visual ones, is Charles Bonnet syndrome. Alroe and McIntyre (1983) described a woman who suffered solely from this syndrome, who visually hallucinated a young girl while also hallucinating a pleasant perfumelike odor.

Olfactory hallucinations in the general population. A recent European survey of 13,057 people chosen at random examined the frequency of hallucinatory experiences (Ohayon, 2000). OHs during daytime were the most frequently reported, with $8.6 \%$ of the sample having experienced them with a frequency of less than once a month. Two other studies of OHs in nonclinical samples have also been undertaken. Kwapil, Chapman, Chapman, and Miller (1996) selected 355 students (out of 8,000 screened) who had high scores on measures indicating psychosis proneness. Twenty-nine of these individuals reported aberrant olfactory experiences $(8.2 \%)$, whereas only $2 / 153$ normal controls did $(1.3 \%)$. Mohr, Hubener, and Laska (2002) found that 13/42 participants had experienced an aberrant olfactory experience (using a looser criterion).

Discussion. OHs are reported in individuals with many different conditions as well as in healthy individuals. Several of their characteristics lend verisimilitude to the claim that $\mathrm{OHs}$ are similar to actually smelling an odorant. First, their hedonic tone is readily apparent, is often reported spontaneously, and is the most salient aspect of the experience, just as it is for real odors (Hinton \& Henley, 1993; Rouby \& Bensafi, 2002). Second, they vary in sensory quality over a similar range to that encountered in normal olfaction (Lawless, 1997). Third, they are attributed to an environmental source in many cases. Fourth, there are several documented reports of appropriate behavioral responses, consistent with the $\mathrm{OH}$ being experientially similar to a real odor. Fifth, in a number of cases, physical examination and olfactory testing revealed no peripheral cause.

There are, however, a number of caveats to this conclusion. First, and most obviously, many of the reports concern individuals with medical conditions, and thus it is difficult to know whether any conclusion might apply to healthy participants. Second, there are some interesting points of difference between actual smelling and OHs, most notably (1) duration, in that some OHs were perceived for long periods of time; (2) foulness, in that unpleasant $\mathrm{OHs}$ dominated reports; and (3) repetitiveness, in that certain OHs occur again and again in the same individual. Third, it is difficult to assign weight to the respective merits of many reports, as they lack investigations of nasal pathology.

\section{Electrical Stimulation of the Brain}

OHs following electrical stimulation are rare, and in the main the experience is described as "vague" with few if any accompanying details (e.g., Andy, 1967; Penfield \& Jasper, 1954; Penfield \& Perot, 1963; Van Buren, 1961). The only detailed report is provided by Nashold and Wilson (1969), who examined electrical stimulation in the thalamus in 5 nonepileptic participants. Three reported unpleasant olfactory experiences - burning, acrid, or chloroform odors; 1 reported pleasant experiencesclove, hay, pear drops, onion, and tobacco odors; and the other, a vague sensation.

\section{Synesthesia}

Setting aside the rich body of material from English literature that suggests synesthetic experiences with olfaction (e.g., Shakespeare's "Sonnet 18" and the opening 
of Twelfth Night ${ }^{1}$ ), Cytowic (2002) has documented several patients in whom olfactory experiences were reported following stimulation to different sensory modalities (see also L. E. Marks, 1978). Unfortunately, all of these examples lack the validation that has been applied to color-word synesthesia, making it difficult to establish the basis for the reported effects. Nonetheless, it is interesting to note the definitional overlap with certain OHs described above (e.g., the combined hallucination of a woman and her perfume) and with examples that are reviewed below (e.g., radio broadcasts of "smell").

\section{Dreams and Hypnogogic Experiences}

There are only four reports of olfactory hypnogogic experiences in the literature (Foulkes \& Vogel, 1965; Leaning, 1925; McKellar \& Simpson, 1954; Schacter, 1976). Only Leaning (1925) provided qualitative data, with reports of rose- and smokelike odors. The olfactory dream literature is also modest. First, a number of reports have made spontaneous mention of olfactory dream content, indicating that such events do occur (e.g., Calkins, 1893; Knapp, 1956; Snyder, 1970; Weed \& Hallam, 1896). Second, Zadra, Nielsen, and Donderi (1998), using both retrospective dream reports and dream diaries, specifically asked participants about dreams with an olfactory content. Around $35 \%$ of men and $41 \%$ of women reported that they had experienced at least one olfactory dream. When dream reports were obtained immediately upon waking, for men only $1 / 897$ dream reports contained an explicit reference to olfaction, whereas for women there were $33 / 2,475$.

Third, in a more detailed study, Stevenson and Case (2005) examined the characteristics of olfactory dreams using retrospective dream reports. Like Zadra et al. (1998), they too found such reports to be infrequent (around $32 \%$ ). Participants were also asked to provide an example olfactory dream and then to rate the characteristics of its olfactory component. When compared with visual dream reports, olfactory experiences were judged to be more emotive, briefer, and less vivid. The olfactory qualities reported covered a wide range, typical of those encountered in day-to-day life. In addition, Stevenson and Case explored whether participants who reported an olfactory dream differed from those who did not by testing odor identification ability. Participants reporting an olfactory dream were significantly better at odor identification, an effect apparently independent of motivation to complete the study or of interest in smell. Finally, participants reporting olfactory dreams scored no higher on a measure of social desirability than those not reporting such dreams.

Discussion. People do report the ability to experience olfactory sensation in dreams, albeit rarely. Rarity might result from the unimportance of olfaction in everyday life (Engen, 1982). Consistent with this are the findings that blind people tend to dream far more frequently of odorous events (Hurovitz, Dunn, Domhoff, \& Fiss, 1999) and that olfactory dreamers report greater interest in their sense of smell (Stevenson \& Case, 2005). The characteristics of olfactory dream images appear to resemble actual smelling: They are brief, emotive, and span a range of qualities. However, these reports need to be taken in the context that hedonic and duration ratings could readily be produced by explicit knowledge about smells. Nonetheless, it is harder to explain why odor identification should be better in olfactory dreamers.

\section{Volitional Imagery}

The first systematic comparison of imagery data from each modality was made by Betts (1909). Using a questionnaire, participants were asked to rate how clear and vivid an image they could form to words describing stimuli drawn from each sensory modality. For olfaction, there were 20 words referring to odorous objects, including roses, cigar smoke, camphor, and burnt meat. In his Experiment 2, Betts reported that ratings for clarity and vividness were poorest for olfactory items when compared with the other modalities. Using an extensively revised version of this questionnaire, Sheehan (1967) obtained the same result.

More recently, K. D. White, Ashton, and Law (1978) produced three different versions of Sheehan's (1967) questionnaire to explore possible confounds relating to question order. For our purposes, they obtained identical results with each version, with olfaction rated as the most difficult to imagine when compared with the other modalities. This finding was replicated (Ashton \& White, $1980)$ with a substantially larger sample $(N=2,640)$. Similar results have also been obtained with samples drawn from different cultures (Marsella \& Quijano, 1974).

Different measurement techniques have also yielded the same pattern of findings. Lawless (1997) asked participants to rate how often they experienced imagery in the following modalities: vision, audition, touch, taste, and smell. Olfaction was the sense in which the fewest people reported frequent imagery and the largest number claimed never to have experienced that form of imagery at all (25\%). Brower (1947) asked participants to imagine the sight, sound, and smell of frying onions. He found that $57 \%$ of participants were unable to imagine the scene's smell, in comparison with only $3 \%$ unable to visualize it. More recently, Lindauer (1969) used the same test and reported that every participant could visualize frying onions, but $30 \%$ were unable to imagine the smell.

The most recent study of volitional imagery compared olfactory experts with nonexperts on their ability to imagine odors (Gilbert, Crouch, \& Kemp, 1998). This study developed its own olfactory imagery questionnaire, in which participants were asked to imagine four odorous "scenes" (e.g., "Think of an outdoor cookout or barbecue ..."), with descriptions of four odorous items taken from that scene (e.g., from the example above, "The charcoal or wood has just been lit and is beginning to burn."). The evocation from each scene was then rated for clarity and vividness. Participants were also asked to complete an established measure of visual imagery that 
had a similar format (the vividness of visual imagery questionnaire, or VVIQ; D. F. Marks, 1973). Two interesting findings emerged: First, mean scores for the visual and olfactory imagery scales were very similarunlike earlier studies - with a moderate correlation between these measures. Second, olfactory experts reported more vivid olfactory images than did nonexperts, although the absolute size of the difference was modest.

The relationship between different forms of imagery is clearly an interesting one. Only one study has explored this topic, by examining the factor structure of Sheehan's (1967) imagery questionnaire (K. D. White et al., 1978). K. D. White et al. observed several factors, one of which was unique for olfaction/gustation. The co-occurrence of the olfactory and gustatory factors is not surprising, as three of the gustatory items were in fact foods with significant olfactory components.

Discussion. Overall, studies of volitional imagery are characterized by three findings: First, some participants report that they can generate olfactory images. Second, factor analysis of imagery ability across modalities suggests a unique olfactory/gustatory factor. Third, these olfactory experiences tend to be both more difficult to form and less vivid than those in all other sensory modalities. These characteristics, difficulty of evocation and lack of vividness, could result from lack of awareness of having formed an image, the unimportance of olfactory experience in day-to-day life, and a lack of practice in forming images (Engen, 1982). Consistent with the latter possibility is the fact that olfactory experts reported more vivid images than did nonexperts (Gilbert et al., 1998). More importantly, Cain and Algom (1997) reiterated a point first made by Aristotle, that smells appear less distinct (vivid) than sense impressions from the other modalities, perhaps in part because an odor's presence is not always confirmable by other means. This may manifest as a greater proneness to report a smell as present when no odor is in fact there, and the literature offers some conditional support for this notion. First, in normal participants aberrant olfactory experiences are reported more frequently than for any other modality (Ohayon, 2000). Second, olfactory studies involving discrimination typically have higher false-alarm rates relative to other modalities (Engen, 1991). Third, Knasko, Gilbert, and Sabini (1990) found differences in ratings of mood, health symptoms, and room odor in agreement with an experimenter's suggestion that a pleasant, neutral, or unpleasant odor was present. Fourth, O'Mahoney (1978) suggested to radio and TV audiences that a sound could induce an olfactory sensation. Listeners called in and reported a large range of odor qualities. Fifth, Slosson (1899) poured water over cotton during a lecture and asked participants to raise their hands when they smelled the odor. Not only did hands initially rise at the front of the audience and spread to the back like a wave, but Slosson had to prematurely terminate the demonstration, as people in the front row were leaving because they did not like the "smell." The implication of these findings is that the relatively lower vividness of olfactory images relative to other modalities could in part reflect ecological differences in perception.

Although the volitional data reviewed above offer an affirmative answer to our first question for this sectiondo participants report olfactory imagery? - the closeness of olfactory imagery to the experience of actual smelling is currently difficult to establish. First, there are no reports of spontaneous affective reactions during olfactory image formation. Second, no one has yet tested whether volitional olfactory images induce affect or, for that matter, any other property (e.g., duration, range of qualities). Nonetheless, it appears likely that some participants can imagine odors on demand.

\section{Section 1 Discussion}

Three questions were addressed in this section: Do people report experiencing olfactory images? Do they report properties akin to those experienced in actual olfaction? Do people behave in accordance with their experience? The first is relatively straightforward to address, as the evidence amassed here suggests that reports of olfactory experience do occur under a wide variety of conditions. The strongest $\mathrm{OH}$ data come from studies that exclude nasal pathology, whereas data from dream imagery are strengthened by the observation that social desirability does not relate to the presence or absence of such reports (Stevenson \& Case, 2005). With respect to volitional olfactory imagery, the factor-analytic study (K. D. White et al., 1978) implied that imagery vividness ratings do not solely result from misattribution of imagery from other sensory modalities. The relatively lower vividness ratings of volitional imagery may reflect ecological aspects of odor perception and difficulty of evocation, as well as lack of practice-an issue we will revisit in the General Discussion section. In sum, although the study base is relatively small, there are no compelling reasons to doubt the veracity of these various self-reports.

The experiential aspects of olfactory images are most clearly presented in OHs and to a lesser extent in dreams, and they have received little attention in the volitional imagery literature. Three characteristics are particularly important: emotiveness, odor quality, and duration. For OHs, the emotive aspect is predominant, often negative, and spontaneously reported in many instances. Qualitative range appears similar to that of actual perception, although duration is considerably more variable, with some OHs lasting hours. Dreams, too, are reported to be more emotive and briefer than visual images, and they also span a range of qualities typical of odors encountered in daily life. For volitional images, few data are available on the range of experiences, or on their temporal or hedonic attributes, either.

The third issue concerns participants' behavior upon experiencing a (primarily) nonvolitional image. The olfactory hallucination literature offers numerous examples, especially for disorders in which the symptoms do 
not usually include bizarre behavior (e.g., epilepsy and migraine). In sum, apart from those with schizophrenia, for whom OHs do not appear to induce appropriate behavioral responses (see above), participants do respond to $\mathrm{OHs}$ as if they were experiencing an odor.

\section{SECTION 2: PERFORMANCE IMAGERY}

This section examines two main issues: First, under conditions in which participants imagine a smell, how similar is their performance to that in an equivalent perceptual condition? Rather than spelling out a list of performance features generated from the extensive experimental literature on olfaction (e.g., Doty, 2001; Lawless, 1997), the approach here is to examine all examples of performance imagery, describe their basis in actual olfaction, and compare their results with the patterns observed in the olfaction literature. In many cases, actual olfactory controls are included, although this raises a general problem that is present in a number of the studies below: A successful demonstration of similarity between an actual and an imagined effect may rely upon a nonsignificant difference between imagery and perception-a null result. It has been argued that such a demonstration of similarity is in itself a striking finding (e.g., Cain \& Algom, 1997); this appears to be a reasonable argument, but only in cases in which the similarity is strongly evident. The second major concern is the cause of any similarity between the perceptual and imaging conditions. This issue is reviewed on a case-by-case basis, with special attention paid to tests of any relationship between phenomenal and performance imagery and to the issue of semantic mediation.

\section{Qualitative Properties}

Multidimensional scaling (MDS) has been used in olfactory research to identify the qualitative dimensions that underlie similarity judgments between pairs of odors (e.g., Schiffman, 1974; Schiffman, Robinson, \& Erickson, 1977). Using this approach, two studies have explored whether the underlying dimensions of real and imagined odors are similar (Carrasco \& Ridout, 1993; Lyman, 1988). A third report (Intons-Peterson \& McDaniel, 1991) provided a brief description of another data set collected by Lyman using a technique apparently similar to that in his original study (see below). Unfortunately, details were not provided about this approach, nor about that in a fourth study (see Shepard, 1975). Consequently, neither report can be reviewed here.

In the first study (Lyman, 1988), participants either completed an imagery phase followed by a real stimulus phase or vice versa. The imagery phase consisted of judging the pairwise similarity of all possible combinations of 10 words representing food and household odors. Participants were told to imagine the smell of each pair of "odors" and then to judge their similarity. This task was followed by rating each imagined odor for 10 bipolar adjectives. A similar procedure was adopted when the
10 odors were actually presented. In addition, all of the participants completed an odor imagery questionnaire based on Sheehan's (1967) scale.

Using replicated MDS, a three-dimensional solution provided the best fit, although not a particularly good one (see Lyman, 1988, p. 32). The bipolar adjective data were used to interpret the MDS solution separately for the real and imagined odors. For imagined odors, Dimension 1 corresponded to pleasant/fruity/fragrant, Dimension 2 could not be identified, and Dimension 3 corresponded to putrid/ burning. For real odors, Dimension 1 corresponded to flowery, Dimension 2 to pleasant/sharp/fragrant, and Dimension 3 could not be identified. As the magnitude of individual correlations between each participant's similarity ratings for real and imagined odors varied considerably, Lyman checked whether any of this variation could be accounted for by participants' ratings on the odor imagery questionnaire. It could not. Lyman (p. 48) concluded that "there was no indication that imagined odors perceptually resembled actual odors."

A second study was conducted by Carrasco and Ridout (1993). This was composed of four phases, each using a different set of participants, but all using the same 16 real or imagined odors. In Phase 1, participants rated the attributes of the real odorants for several dimensions (e.g., pleasantness, familiarity, foodlike, etc.). In Phase 2, a different set of participants judged the pairwise similarity of all possible combinations of the odors. MDS revealed three dimensions-pleasantness/fruitiness (Dimension 1), intensity (Dimension 2), and familiarity/spiciness (Dimension 3). The qualitative basis for these dimensions was calculated by using the attribute data obtained for each of the odors in the first phase of the experiment. The third phase of the experiment was identical to Phase 1, and the fourth phase to Phase 2, except that names corresponding to the real odors were employed instead.

A three-dimensional solution appeared the best fit for the imagined odor similarity data. The first dimension was best characterized by fruitiness/spiciness and correlated substantially with Dimension 1 from the real equivalent odor condition. However, pleasantness did not appear a significant component of this judgment, in that the imagined attribute of pleasantness from Phase $3 \mathrm{did}$ not correlate with Dimension 1 of the imagined odor condition, unlike for the real stimuli. Dimension 2 was best characterized by strength - as was also the case for real odors - but this dimension did not correlate with its real equivalent. Finally, the third dimension correlated moderately with its real equivalent and represented familiarity for the imagined odors and familiarity and spiciness for the real odors.

Discussion. Both of these MDS studies provide some evidence of similar perceptual spaces generated by real and imagined odors. First, Lyman (1988) found that pleasantness was a primary dimension in the imagined odor condition, a finding that is consistent with MDS studies of real odors (e.g., Schiffman, 1974; Schiffman et al., 1977). 
Second, Carrasco and Ridout (1993) observed considerable overlap between the perceptual and imagined conditions, which was perhaps all the more remarkable because they used a between-participants design. However, the studies feature some interesting differences from each other, too. Lyman concluded that there was little overlap in the MDS solutions for real and imagined odors, a conclusion completely at odds with that reached by Carrasco and Ridout. In addition, in the latter study the researchers did not obtain a pleasantness dimension with their imagined odors.

A second issue concerns the degree to which the observed similarities arose through attempts to imagine odors, rather than from drawing upon explicit knowledge or visual imagery. Carrasco and Ridout (1993) argued that neither of the latter two factors could account for their results, mainly because some of the odor groupings appeared difficult to explain on the basis of what people might know or could visualize (e.g., leather, gasoline, and menthol clustered). Nonetheless, it is important to note that no experimental manipulation was conducted to rule out these alternatives. Finally, Lyman's (1988) failure to obtain a relationship between phenomenal imagery and performance is surprising, as this type of relationship has been obtained in comparable visual imagery studies (e.g., McDermott \& Roediger, 1994; McKelvie, 1995).

\section{Psychophysical Properties}

Several studies have explored whether olfactory psychophysical laws obtain under conditions in which the odors are imagined. Many of these studies use a similar technique, in which an odor is associated with a colored card that is later used to represent the odor, so that the participant knows which one to evoke-memory psychophysics. The first investigation of this type was made by Osaka (1987), who had participants learn associations between each of six different colors and six different concentrations of pyridine. During the learning phase, participants rated the intensity of pyridine, and later they rated the intensity of imagined pyridine when they were shown the associated colors alone. There were both similarities and differences between the two conditions. Perceived intensity grew as a power function of concentration in both conditions, with the imagined exponent being less than 1 and thus within the range typically encountered in olfaction (Lawless, 1997). However, the slopes significantly differed, with a steeper gradient in the imagined condition.

Osaka's (1987) finding was taken further in a series of studies conducted by Algom and Cain (1991). In their first experiment, they had a group of participants learn the relationship between five concentrations of banana odor and five differently colored cards. Unlike in Osaka's study, participants' color-odor training was more carefully evaluated (as it was for all of the experiments reported from this series), so any deviations from the comparison condition who received real stimuli were unlikely to result from differences in training. On the following day, participants were randomly assigned to either a mental imagery or a real stimulus condition and asked to rate intensity. The power functions obtained for real and imaginary stimuli were not significantly different, suggesting considerable similarity between the real and imagined conditions.

In the second and subsequent experiments, Algom and Cain (1991) explored a considerably more interesting phenomenon. A mixture of two odorants (homomodal) is generally judged to be less intense than the sum of its parts (Lawless, 1997). Algom and Cain set out to test whether this would hold true if the mixtures were imagined. One group of participants learned the relationship between factorial combinations of three concentrations of banana odor and three of crushed grass odor using colored cards. Each colored card was then presented and judged for intensity. A second group of participants repeated this rating task for the equivalent real mixtures and single stimuli. Algom and Cain obtained a high level of concordance between conditions, in that the most concentrated solutions in both conditions, when mixed, were judged to be less intense than the sum of their parts.

Participants in the imagery condition described above had actually experienced the mixtures. For our purposes, the most revealing results come from their final three experiments. In these experiments, participants learned associations between two concentrations each of banana odor and crushed-grass odor and four colored cards. In the test condition, participants were asked to rate the intensity of the individual colored cards and of pairs of cards, the latter representing combinations that they had never actually experienced. Interestingly, the same pattern of findings observed in Experiment 2 was again obtained. A further experiment was then conducted using semi-mental mixtures, in which one component on test was a real odor and the other was a colored card with a previously learned odor referent. Performance here was also very similar to that obtained in the preceding two experiments. In sum, when participants imagined odor mixtures that they had not previously encountered, they appeared to be bound by the same rules of homomodal mixture integration that govern real olfactory stimuli.

Algom and Cain's (1991) final experiment examined a further aspect of mixture psychophysics: When two odors are mixed, the perceived magnitude of the constituent odor qualities is reduced (Cain, 1978). For this experiment, participants were split into two groups, one of which learned the relationships between four concentrations of banana odor and four colors. This group was then asked to smell two concentrations of crushed grass that were factorially combined with each of the four imagined concentrations of banana. When judging each factorial combination, the following procedure was adopted: Participants first smelled the banana odor and judged its intensity. The colored card representing that concentration of banana was then presented while the participants sniffed the relevant concentration of crushed 
grass odor. Their task once again was to judge the intensity of the banana odor in this semi-mental mixture. Another group of participants completed an identical task, but this time using real stimuli. There was considerable similarity in the results obtained in each condition: Stronger concentrations of crushed grass were more effective in reducing the intensity of banana, but they became less effective when the banana odor was more concentrated.

With odor mixtures, as noted above, the judged intensity of both the components and the overall mixture is reduced relative to the unmixed elements (Lawless, 1997). However, mixtures of tastes and odors (heteromodal) do not have a similar effect; instead, their components demonstrate additivity. More importantly, participants do not regard stimuli in the mouth as involving both smell and taste but as taste only. The question then arises whether participants will behave in a manner consistent with stimuli belonging to one sense (i.e., as above) or respond to the stimuli correctly, but contrary to their "one-sense view," as a heteromodal mixture (i.e., component additivity). Algom, Marks, and Cain (1993) had participants learn associations between two concentrations of orange flavor and two colors and between two concentrations of sucrose and two further colors. Later, participants were randomly assigned either to an imagery condition or to a condition in which they sampled the real stimuli and mixtures. In the mental mixtures condition, participants were asked to imagine sampling each of the stimuli and the mixtures of stimuli, but only the colored cards were presented. Participants were then asked to rate the overall intensity of each stimulus or combination. Participants in the real condition performed an identical task, except they were exposed to the real stimuli. The mixtures in both the real and the perceptual conditions showed linear additivity - that is, the mixtures were treated as the sum of their component intensity ratings. Not only do these results show considerable consistency between imagery and perception, but they are inconsistent with the use of explicit knowledge, as this would have predicted the same pattern as for homomodal odor mixtures, since participants (falsely) believed these stimuli to be homomodal.

A further study by Stevenson and Prescott (1997; Experiment 2) explored interactions among taste, odor, and the trigeminal sense. The focus of this study was primarily directed at detecting the influence of explicit knowledge on performance. Prescott and Stevenson (1995) had noted that participants thought that capsaicin, the pungent principal of chili, suppressed their experience of "taste" (i.e., taste and smell). However, laboratory work indicated that the effects of capsaicin were specific to sweetness but not to retronasal olfaction. Stevenson and Prescott set out to explore how the semimental mixture procedure described above would affect ratings. On the first session, participants learned an association between the capsaicin vehicle and one color and a 16-ppm capsaicin stimulus and another color. On a second session, they were presented with a real mixture of sucrose, citric acid, and an orange flavorant and asked to imagine mixing the vehicle stimulus with it. Ratings of sweetness, sourness, and flavor intensity were obtained. This procedure was then repeated, but this time the participants were asked to imagine adding the capsaicin stimulus. On a third session, only the odor-taste mixture was presented and rated. On a fourth session, the real stimuli equivalent to those in the second session were used and rated. Although participants reported on a postexperimental questionnaire that all three ratings would be reduced by the presence of capsaicin, only ratings of sweetness were affected for both of the imagined mixtures and in the real condition, suggesting a dissociation between their beliefs and their behavior.

In the most recent psychophysical investigation of olfactory imagery, Baird and Harder (2000) examined whether olfactory images generated by a series of written descriptions (e.g., shampoo in a person's hair) could elicit magnitude estimates of intensity and cross-modal matches to visual and auditory images that shared statistical characteristics with known properties of real magnitude estimates and cross-modal matches. Overall, there was a high degree of consistency between imagery ratings and those for real stimuli. The only exceptions were sequence effects, which were reduced relative to the real stimuli; Baird and Harder attributed this result to the greater information available in the imagery condition.

Discussion. The psychophysical properties of odor images are similar to those of real stimuli: They are best fit by power functions; demonstrate suppression and additivity; and have statistical properties that are indistinguishable, excepting sequence effects, from judgments of real stimuli. However, two related questions require consideration. First, to what extent do these results arise from explicit chemosensory knowledge? Second, to what extent do they arise from phenomenal imagery versus some other form of representation? Although it is possible to argue that explicit knowledge about the chemosensory world may underlie these effects, at least one study attempted to address this argument directly and found that participants' knowledge (elicited using a questionnaire) provided a different pattern of results from that obtained in an imagery versus real perception experiment (Stevenson \& Prescott, 1997). Similarly, the outcome from Algom et al.'s (1993) study is contrary to what one might expect on the basis of the use of explicit knowledge. Nonetheless, others have argued that explicit knowledge may be the basis upon which such judgments are made. Schifferstein (1997), using combinations of tastes, found that participants asked to imagine mixtures produced responses that, despite bearing an overall similarity to ratings of real taste mixtures, differed importantly in detail. Setting aside the issue of whether it is appropriate to generalize from one sensory modality to another (see Cain \& Algom, 1997), such differences are 
arguably evidence of incomplete explicit knowledge about the way in which taste mixtures behave.

The second question we posed followed from the first: If not explicit knowledge, what form of representation underlies these effects? No direct data pertinent to this issue were presented in any of these studies; for example, no attempts were made to establish relationships between measures of phenomenology and performance. The only guide is that several studies include anecdotal reports of how participants went about the tasks. In some cases, the use of phenomenal imagery was reported (Baird \& Harder, 2000; Stevenson \& Prescott, 1997).

\section{Cognitive and Perceptual Properties}

The effect of imagining an odor on subsequent cognitive and perceptual tasks has been examined in several studies. Lyman and McDaniel (1990, Experiment 2) explored whether imagining odors would improve performance on an odor recognition task. In Phase 1, half of the participants were asked to form olfactory images from a set of 20 written words representing household and food odors. The second group were asked to visualize these same items. Both groups rated the clarity of their images. In Phase 2, participants from each group were assigned to one of two new groups: (1) an odor recognition condition, in which 40 odors were presented, of which 20 were the olfactory equivalents of the words in Phase 1; and (2) a visual recognition condition, again composed of 40 pictures, of which 20 represented items from Phase 1. The participants' task in each case was to identify items as either "old" or "new." Recognition was assessed using $d^{\prime}$, and this analysis revealed that performance was better for both the visual and olfactory imagery conditions when both the imagery and recognition conditions focused on the same modality. Moreover, image clarity correlated with recognition performance, but only when the two modalities were the same. Lyman and McDaniel concluded that these results suggest modality-specific imagery systems.

Not all investigators agree with this interpretation. Herz and Engen (1996) noted that the recognition effect described above was not significant when hit rate alone was examined and that it originated primarily from differences in false-alarm scores. On the basis of this result, Herz and Engen (p. 305) suggested that "olfactory verbal codes (as opposed to olfactory sensory codes) were activated by the odor imagery instructions, and these codes were more closely associated to olfactory experience than visual imaginal codes were." The correlation data do pose a problem for this alternative account, as it is difficult to see why participants with better performance should rate their olfactory images as clearer if the effect was based on generating an olfactory verbal code. Nonetheless, since Lyman and McDaniel (1990) did not run a verbal rehearsal/encoding condition, no definitive conclusion on this point can be drawn from Lyman and McDaniel's study.

Herz (2000, Experiment 2) also examined the similarity of imaginal and perceptual olfactory codes. Partici- pants were incidentally exposed to six olfactory-picture pairs (i.e., smell an odor while looking at a picture) and six "imagine the odor"-picture pairs. In the imagine condition, participants were told to form a mental image of the odor. Following a short break, participants received a test phase in which four types of stimuli were presented: (1) three odors drawn from the six used in training; (2) three words representing the other three odors used in training, with participants being asked to imagine the odor; (3) three words used during the six imagine odor-picture pairings, with participants asked to imagine the odors again; and (4) three odors corresponding to the three odor words used during the imagine odor-picture condition. For each stimulus, participants were asked to describe the picture that went with that stimulus. Herz found that switching the cue on test had a deleterious effect on recalling the pictures (i.e., moving from imagined odor to real odor, or vice versa). Although these findings are based on a null result (i.e., no interaction between stay/shift and cue type), they are consistent with Herz and Engen's (1996) alternative account of Lyman and McDaniel's (1990) results-parti-cipants do not form perceptlike olfactory images.

A similar conclusion was reached in three experiments reported by Schab (1990), who investigated whether an odor present during the learning phase of a word list would facilitate recall. Although real odors did provide facilitation, imagining them had no effect, even though participants reported success at generating olfactory images.

Crowder and Schab (1995) reported three experiments in a chapter on odor imagery. In the first experiment, participants smelled 15 odors and were told to memorize them for a later test. The participants were then assigned to one of four conditions prior to a recognition memory test: (1) a control condition in which participants received no treatment; (2) an odor condition in which they smelled a further 15 odors that they were told to remember; (3) an odor imagery condition in which they had to imagine 15 odors from words and remember them; and (4) a visual imagery condition in which they received the same words but had to visualize and remember them. Overall, there were no significant effects of odor imagery on recognition memory performance. However, in female participants there was evidence of lower $d^{\prime}$ scores in the odor imagery condition, suggesting an effect in this group.

Crowder and Schab's (1995) second experiment only included female participants, on the basis that females may be better at forming images. The participants were assigned to either a visual or an odor imagery group and were asked to form images to a set of 50 object names. Following a short break, participants were presented with 20 odors corresponding to 20 of the objects in the imagery phase. The participants' task was to identify the odors. This was followed by a recognition memory test for the object names presented in the imagery phase. Although there was no effect of imagery condition on the odor recognition task, the odor imagery group were significantly better at recognizing the names of the object 
words that had been presented in the imagery phase. Crowder and Schab suggested (p. 101) that this result may indicate "that when motivated to form an olfactory image, people engage some nonolfactory, possibly semantic, form of processing." Finally, Crowder and Schab tested whether odor imagery would enhance odor detection, using the ascending method of limits. In a withinparticipants design, participants engaged in detection trials while either imagining the target odor or not imagining it. No effect of imagery was obtained.

In a brief review of odor imagery, Elmes (1998) described a further attempt to demonstrate imagery using a recognition memory procedure. In Phase 1, participants looked at a series of 20 pictures depicting odorous objects. Half of these participants were asked to name the objects, whereas the other half were asked to imagine their smells. Finally, all of the participants, including a control group who had not participated in Phase 1, were asked to name a set of 20 odors, 10 of which had been depicted earlier. Both the group that had named the objects in Phase 1 and the group that had imagined the smell identified significantly more odors in the recognition test than did the control group. However, there was no significant difference in recognition performance between the object naming and odor imagery groups.

Djordjevic, Zatorre, and Jones-Gotman (2004) examined whether real and imagined odors affected detection accuracy of a real tastant. The motivation for this study was based on the synergy between certain taste qualia (here, sweetness) and certain olfactory qualia (also sweetness; see Frank \& Byram, 1988). In Experiment 1, using a between-participants design, they first estimated each participant's detection threshold for sucrose. In the second phase, participants were randomly assigned either to an imagery or a real-perception condition. Both groups were then given ham and strawberry odors to smell, and the imagery group were asked to practice imagining them after sniffing each real odor. In the third phase, participants received 90 trials, each of which involved picking which out of two solutions tasted stronger. One contained that person's threshold-level concentration of sucrose, and the other, water. On one third of the trials, participants either sniffed or imagined ham odor before tasting each of the two solutions; on another third, strawberry was either sniffed or imagined prior to tasting; and on the final third, no odor or imagining was required. Djordjevic et al. found, first, that strawberry had no effect on detection accuracy in either the real or the imagined condition; second, that ham significantly reduced detection accuracy in both conditions; and third, that the imagery and real-perception conditions did not differ. These findings were replicated in a second experiment using a within-participants design.

Although their conclusions were based on a null result and an unexpected finding (no effect of the "sweet"smelling odor), the authors concluded that imagined odors have features similar to actual odors. Nonetheless, some caution might be necessary here, as the design cannot exclude generalized imagery effects that might have produced the same result irrespective of modality. That is, attempts to visualize "ham" might have the same consequence as attempting to imagine its smell (see Segal \& Fusella, 1971, for a conceptually similar issue in a visual task).

This criticism has been most effectively addressed in a further study by Djordjevic, Zatorre, Petrides, and Jones-Gotman (2004). In this study, participants were first assessed for their thresholds for lemon and rose odors. They were then assigned to one of three experimental conditions: olfactory imagery, visual imagery, or a no-imagery control. The olfactory imagery group were asked to smell lemon and rose odors until they reported success at forming images. The same procedure was adopted for the visual imagery condition, except that in this case participants were shown photographs instead. Participants in the imagery conditions then responded to the vividness of olfactory imagery questionnaire (VOIQ) and the VVIQ (visual imagery); these questionnaires were completed at the end of the experiment by the nonimagery control group. All participants were given forced choice detection trials composed of their threshold level for the target odor versus a water blank. Participants in the imagery conditions were asked to imagine (with an olfactory or a visual image, respectively) either lemon or rose prior to sniffing the bottles. On $50 \%$ of trials, the imagined stimulus and the odor were matched, and on $50 \%$ they were mismatched. Control participants received no cues. Two findings are of interest: First, odor imagery significantly interfered with detection accuracy but did not facilitate it, relative to the control condition. Visual imagery had no effect. Second, although the VOIQ was not correlated with overall performance, it did significantly correlate with the performance of female participants, offering some evidence that self-report of phenomenal imagery ability was related to task performance. These results offer compelling evidence in favor of olfactory imagery; the findings are not based on a null result, they exclude a generalized imagery effect, and the remaining possibility (that the effect emerges from semantic mediation), although it was not completely excluded (no verbal-cue-alone condition), appears unlikely because of the use of cue words to evoke visual images that exerted no effect.

Discussion. Three studies offer evidence for imagery: Lyman and McDaniel's (1990) Experiment 2 and Djordjevic and colleagues' (Djordjevic, Zatorre, \& JonesGotman, 2004; Djordjevic, Zatorre, Petrides, \& JonesGotman, 2004) studies. Although the first- and secondmentioned studies are potentially open to alternative explanations based on semantic processes or generalized effects of imagery, such explanations are unlikely to account for the third, and two of the reports also found relationships between phenomenal imagery and task performance. However, other studies are not consistent with 
olfactory images having much resemblance to actual olfactory perceptual codes. Rather, most olfactory images can and have been attributed to some form of semantic processing.

\section{Brain Imaging}

Four studies have examined whether olfactory imagery yields similar patterns of brain activation to those produced by physically present olfactory stimuli. Lorig and Roberts (1990) falsely cued participants about the type of odor they were about to smell. For example, in some conditions participants were led to expect jasmine but were presented with a mixture of three test odors (jasmine, galbanum, and lavender). On other trials, the warning was followed by the correct odor. In all cases, EEG recordings were made for a 3-sec period following the termination of the odor. Lorig and Roberts found that when participants were "falsely" cued, the pattern of EEG activity produced for two out of the three odors used was very similar to that produced by the actual odor the participants thought they were going to smell. One interpretation of this result is that participants expected a particular smell and consequently produced a pattern of neural activity similar to that produced by the actual odor.

A similar finding has been reported by Barabasz and Gregson (1979), who studied suggestibility in a group of over-wintering Antarctic participants. EEG activity to real and suggested odorants was assessed both fairly soon after arrival at Scott Base and following an extended period of isolation due to winter. They found that EEG amplitude suppression, normally observed upon real stimulation, increased for suggested odors across the two time periods, whereas response to real odors exhibited the reverse trend. Barabasz and Gregson claimed that the results reflected the use of imagery ("signal generation," in their terms), since evidence for alternative explanations, such as the "verbal framework" (by which they presumably meant the instructions for both suggested and real odors), was identical between conditions, and criterion shift was excluded by the similarity of reaction times on the EEG to real and suggested odors.

Levy, Henkin, Lin, Hutter, and Schellinger (1999) had both normal participants and three anosmics imagine and smell two odors while their brains were being imaged. For clarity, only the data for the normal participants are reported here, although it should be noted that the anosmics' imagery data did not differ in any substantial respect. Participants were asked to imagine ripe banana and peppermint and were then presented with the real odors. During both the imagery and odor phases, participants were scanned using fMRI. The images revealed substantial overlap in the areas activated by real and imagined stimuli, but all activations were reduced in the imagery condition.

Henkin and Levy (2002) reported a further fMRI study that used the same design described above for its olfactory component. However, this study compared congenital anosmics - that is, individuals who had never been able to smell — with normal controls. Unlike in their previous study, separate data were not reported for the controls. What makes this study of interest is that in the Levy et al. (1999) study, the anosmic group were able to imagine odors in a manner akin to normal controls. For Henkin and Levy, attempts at imagery produced very little activation in the congenital anosmics. Henkin and Levy suggested that this was because the congenital anosmics had no odor memories upon which to draw.

Discussion. All of these studies suggest a correspondence between imagery and perception; however, neither of the fMRI studies controlled for any effect of sniffing. As sniffing is known to activate many brain areas identified in olfactory perception (Sobel et al., 2000), there must be some concern that the results in these studies could be attributed solely to sniffing, although the data from congenital anosmics may argue against this. Two studies have reported that sniffing does occur when trying to form an image (Bensafi et al., 2003; Perky, 1910), and the latter study implied that this sniffing may be essential.

\section{Section 2 Discussion}

To what extent can imagining an odor produce effects akin to smelling it? Data were reviewed from four domains - odor quality, psychophysics, cognition and perception, and brain imaging. Examples of correspondence were observed in all cases, although two caveats do apply: First, many findings, both for and against, were based on null results. Second, when correspondences were observed, there were often competing explanations. These explanations included explicit knowledge of the way these systems behave, semantic processing, and nonspecific effects due to imagining in general or to the process (sniffing) involved in forming an image. The only study to escape all of these alternatives is Djordjevic, Zatorre, Petrides, and Jones-Gotman (2004), which offers convincing evidence for imagery.

Evidence favoring a role for phenomenal imagery in these various domains was provided by Lyman and McDaniel (1990), thus adding weight to their claim that phenomenal imagery mediated the effects of tasks in these domains. Lyman (1988) failed to observe any such relationship in his MDS study, whereas Djordjevic, Zatorre, Petrides, and Jones-Gotman (2004) did. Lyman and McDaniel's data point to the importance of trying to demonstrate a link between phenomenal olfactory imagery and performance, as such a relationship could strengthen the claim that any effects observed do involve perceptlike images.

\section{SECTION 3: CUED IMAGERY}

This section examines the interaction of past olfactory experience - cued images - with current perception. Unlike the preceding two sections, this review is not exhaustive, as the existence of these types of effects is widely acknowledged and is supported by a fairly extensive basis of evidence (see, e.g., Dalton, 1996, 1999; 
Tuorila, Cardello, \& Lesher, 1994). However, what is of greater interest is whether cued images are essentially perceptual or semantic in nature. Note how this interest coincides with the performance imagery section above (i.e., ruling out nonperceptlike accounts and the relationship of performance to phenomenal imagery) and also how it is central to determining whether cued images are images or just alternative ways of describing the same percept (i.e., a semantic phenomenon). This section is organized around the types of cues used to generate the effect, and these can be broadly separated into two classes: (1) when nonolfactory and olfactory cues are both present (heteromodal cues) and (2) when only olfactory cues are present (homomodal cues).

\section{Heteromodal Cues}

The most well-developed body of data concerns the impact of color on odor perception. Engen (1972) asked 3 participants to identify when an odor was present or absent using a signal-detection paradigm. The addition of color to blank stimuli increased the false-alarm rate, suggesting that color misled participants into judging an odor to be present when in fact it was absent. The nature of this type of effect has been explored more extensively using superthreshold stimuli. Dubose, Cardello, and Maller (1980) found that odorless colors added to either drinks or food (cake) increased rated flavor intensity. More interestingly, they also observed that atypical colors (e.g., orange-colored cherry-flavored drinks) induced flavor ratings that were characteristic of the flavor normally associated with that color (see also Hyman, 1983).

Not only does color affect participants' judgments when it is integral to the stimulus, it affects identification even when it is presented discretely alongside the stimulus. Davis (1981) asked participants to identify odors either alone, with a colored chip, or with a color's name (i.e., red). Color facilitated identification if it was relevant, whereas irrelevant colors increased incorrect identifications. Words were more effective than colored chips. Identification is also affected if the odorant itself is colored. Zellner, Bartoli, and Eckard (1991) found that appropriate colors, such as a red cherry-flavored solution, increased identification rates and decreased response latencies. In this case, inappropriate combinations had no effect.

The effects of color seem to occur independent of the demand characteristics of the situation. Zellner and Kautz (1990, Experiment 1) found that certain color-appropriate combinations with odors were rated as more intense than the odor alone. Their second experiment used a more demand-free test, in which a standard olfactory stimulus was colored for half of the participants and uncolored for the remainder. Participants' task was to judge whether the standard stimulus was stronger or weaker than a range of comparison stimuli, some of which were stronger, some the same concentration, and some weaker. For participants who had a colored standard, the comparison stimuli were all uncolored, and vice versa. Importantly, this procedure can be considered relatively demand free because participants were not directly rating intensity, which might have served as a cue to what the experimenter expected. Zellner and Kautz found that a significantly higher proportion of participants judged the colored solution to be stronger smelling. In a third experiment, they found that inappropriate colors were just as good at increasing intensity ratings as were appropriate colors, suggesting that the effect, at least for intensity, is nonspecific.

Color has been shown to affect the qualitative characteristics of an odor in an even more dramatic way. Morrot et al. (2001) found that participants' qualitative evaluations of a white wine colored red by an odorless and tasteless colorant more closely resembled the characteristic evaluations of red wine than of either white wine or colored white wine presented in opaque containers. Building upon this finding, Gottfried and Dolan (2003) presented participants with either congruent olfactory-visual information (i.e., diesel odor and a picture of a bus), incongruent olfactory-visual information (i.e., fish odor and a picture of cheese), or an odor or visual stimulus alone. The participants' task was to judge whether an odor was present or not. Response latencies were shorter when the bimodal stimuli were congruent than when they were incongruent or when the odor was presented alone.

Labels too can exert effects similar to those of color. Moskowitz (1979) found that presenting brand labels for perfumes increased ratings of liking. A more recent investigation by Herz and Clef (2001), using odors deliberately chosen for their hedonic ambiguity, found that the verbal label presented with the odor when it was hedonically evaluated exerted a significant effect on pleasantness ratings. In a within-participants design, participants judged, for example, a mixture of isovaleric and butyric acid to be more pleasant when it was described as Parmesan cheese than when it was labeled as vomit. Although demand characteristics could clearly affect the outcome of this type of experiment, the finding of a "first-label" effect would appear to make this less likely. This is because for certain odors, the first label presented influenced participants' judgments later, when the same odor was presented again with a different label. This occurred for both pine (labeled Christmas tree vs. spray disinfectant) and menthol (breath mint vs. chest medicine). If the label exerted its effect by demand, then order would not be expected to play a significant role.

Not only can the presence of a label affect liking, it can also influence judgments of familiarity and intensity. Distel and Hudson (2001) found that when odors were presented without labels, they were judged to be significantly less pleasant, less intense, and more unfamiliar than when presented with a label. More generally, the effect of learning an odor's name is known to increase its discriminability from other odors (Rabin, 1988, Experiment 2). One possible interpretation of this result is that 
odors are perceived "more sharply" when their identity is known (Distel \& Hudson, 2001).

Discussion. Clearly, nonolfactory cues such as color or verbal labels can affect participants' reports of odor intensity, quality, and hedonics. To what extent can these effects be attributed to perceptual rather than semantic mediation? In some cases, the effects on participants' behavior were clearly "demand free." Findings that argue against a demand account include, for example, Engen's (1972) discovery that feedback exerted little effect on false-alarm rates; Zellner and Kautz's (1990) observation, using a comparative measure of intensity, that color still influenced the perceived strength of odors; and Herz and Clef's (2001) observation of a first-label effect. In other cases, misidentification resulting from the presence of a color or word cue may have led participants to behave as if the odor was something else (e.g., Dubose et al., 1980; Hyman, 1983; Morrot et al., 2001). However, in all of these cases, no definitive data allow us to conclude that the representation generated by the cue was perceptual in nature. Evidence favoring a semantic explanation is provided by one study: Gottfried and Dolan (2003) argued that because response latencies were shorter only in the congruent condition and were not different between incongruent and odor-alone conditions, semantic associations between the odor and visual image mediated the effect.

\section{Homomodal Cues}

Simply being exposed to an odor, whether alone, mixed with another odor, or mixed with a taste, can subsequently alter perception of the odor. Rabin (1988, Experiment 1) had participants profile a set of seven unfamiliar odors using the Dravnieks (1985) set of scales. In a subsequent discrimination test, their performance was significantly better than that of the two nonexposed control groups. A similar result was obtained by Jehl, Royet, and Holley (1995), who gave groups differing exposures to sets of unfamiliar odors. On test, discrimination increased with exposure.

Casual observation suggests that sweet-smelling odors tend to have a history of co-occurrence with sweet tastes. This implies that if a relatively unfamiliar odor dissolved in sucrose solution was presented to participants, this odor too might acquire the property of "sweetness." Such a finding has now been obtained in several studies (Stevenson, Boakes, \& Prescott, 1998; Stevenson, Boakes, \& Wilson, 2000a, 2000b; Stevenson, Prescott, \& Boakes, 1995). Likewise, pairing the same odors with citric acid (using different participants) can result in the odor smelling sourer (Stevenson et al., 1998; Stevenson et al., 1995). In all of these experiments, considerable attention was paid to masking the true purpose, and as all measures of learning appeared unrelated to those of awareness, both the learning process and the perception of tastelike qualities are probably automatic (Stevenson \& Boakes, 2004).

Although the acquisition of tastelike properties by odors appears robust, three issues are potentially prob- lematic. The first concerns "halo dumping," in which perceptually similar odor qualities are conflated onto the same rating scale. For example, fruitiness commonly cooccurs with sweet tastes, so when participants are asked to rate the sweetness of a fruity odor, in the absence of a fruitiness rating, they dump "fruitiness" into the "sweetness" rating, making the odor seem sweeter than it would have if fruitiness had also been taken into consideration (Clark \& Lawless, 1994). More recent evidence (van der Klaauw \& Frank, 1996) suggests that halo dumping reflects a decision effect about how an odor's qualities are partitioned (e.g., "Is this sweet or fruity?") and that it does not tell us anything about which qualities may or may not be present in an odor.

Two other issues are also pertinent. First, participants may use the term sweet as a metaphor for liking. Although this account is difficult to refute because the crucial tests have not yet been carried out, it too appears unlikely. This is because in all published studies of odor-taste learning, liking ratings rarely register any change in preference for a sucrose-paired odor, whereas the odor sweetness effect has always been obtained (Stevenson \& Boakes, 2004). A further concern is the degree of correspondence between the sensation of sweetness engendered by an odor and its corresponding analogue, tasted sweetness. Recently, Rankin and Marks (2000) observed that sweet-smelling odors do not affect intensity judgments of sweet-tasting odors. Interestingly, their data suggested that even though participants felt that sweetsmelling and -tasting odors were perceptually similar, this did not translate into the odors providing an appropriate judgmental context for evaluating the intensity of tasted sweetness. Clearly, these results suggest that although the qualia may overlap substantially, there are constraints.

Not only can past experience influence perception of "tastelike" qualities, it can also affect participants' experiences of more typical odor qualities. Pairing two odors together can result in those two odors coming to smell more alike (Stevenson, 2001a, 2001b, 2001c; Stevenson, Case, \& Boakes, 2003). For example, after smelling a mixture of cherry and guaiacol, smokysmelling guaiacol is rated by participants as smelling more cherrylike and cherry as smelling more smoky than is true for equally exposed controls (Stevenson, $2001 \mathrm{~b}$ ). The important point to note here is that cherry (or guaiacol) in this example has a perceptual attribute that was not originally associated with that sensory input, just as with odor-taste learning, in which an odor comes to smell sweet even though sweet was not initially a salient attribute of the stimulus. This breakdown in the relationship between stimulus and percept has been demonstrated for a number of different odors and qualities and detected by several different types of measure, including discrimination (Case, Stevenson, \& Dempsey, 2004; Stevenson, 2001c).

Discussion. As with the heteromodal cue data, there does not appear to be any strong evidence favoring demand as an explanation. As to whether the effects de- 
scribed above have a perceptual or a semantic basis, the weight of evidence would appear to favor the former, for two reasons: First, many of the odor stimuli were unfamiliar, making identification of the stimuli difficult. Thus, it is hard to account for these results in terms of verbal knowledge (e.g., "odor $X$ was paired with sweet"). Second, most of the studies described above relied upon perceptual-level confusions, and thus upon discrimination, unlike the heteromodal studies. Although verbal labeling can play a role during discrimination, it is less likely to do so when the stimuli are hard to identify. In sum, although no study as yet has employed methods that expressly rule out a semantic account, the representations generated by these homomodal cues do appear to be perceptually based.

\section{Section 3 Discussion}

There can be little doubt that both heteromodal and homomodal cues affect the way in which an odor is described, and unlike with the performance imagery data, converging evidence supports this conclusion. The most pertinent issue, though, is whether these effects reflect the operation of a perceptual (imagelike) or semantic code. For heteromodal cues, there is as yet no decisive evidence. For homomodal cues, the weight of evidence appears to favor a perceptual code. For such cues, at least, an olfactory cue seems able to trigger a perceptlike image.

\section{GENERAL DISCUSSION}

The most important empirical and theoretical issue identified in this review is the difficulty that participants have in evoking olfactory images, which has implications for the key question that we have considered at length: Do olfactory images resemble actual olfactory percepts? First, consider the pressing concern over whether perceptual or semantic representations underlie similarities observed on some performance imagery tasks. If many participants are unable to follow the experimenter's instruction to form an olfactory image, they will likely use whatever strategy they can to complete the task. If the aim of a study is to detect nonimaginal strategies, that is exactly what will be found if many participants cannot evoke an image. The same argument applies to the study of volitional imagery: We do not know the degree to which participants misattribute success at forming visual images to their success at forming olfactory ones, an issue that is a real concern given the correlation observed between visual and olfactory imagery (e.g., Gilbert et al., 1998). Nor do we know whether the characteristics of volitional imagery resemble routine olfaction, especially the hedonic aspects that are typically so prominent. Yet, if many participants are unable to evoke olfactory images, it would not be surprising if they used alternative strategies. One could of course argue that difficulty of evocation simply reflects the inability of participants to generate olfactory images. However, as we argue below, there are good theoretical reasons to expect difficulty of evocation, and these theoretical grounds lead directly to empirical strategies that could be used to improve it. If these strategies work, and evidence already presented in this review suggests that they might, then much of the ambiguity about olfactory imagery's perceptual or semantic basis - and indeed, its existence - could be dispelled.

Another important issue for the study of olfactory imagery is its neural correlates. Conceptually similar studies in visual imagery have been highly informative, and they provide an important empirical basis for Kosslyn's depictive theory of imagery (Kosslyn \& Thompson, 2003). Several interesting questions arise: First, olfactory neuroimaging studies have started to explore localization of specific olfactory functions (Royet et al., 2001). To what extent are the same brain areas involved in imageryequivalent tasks, especially those involving affect? Second, the roles of visual and semantic processes in olfactory imagery need to be explored in order to assess the degree to which brain areas associated with these functions are selectively active in imagery but not in equivalent olfactory tasks. Third, although neuroimaging results may be instructive, cognitive neuropsychology may provide equally crucial insights. With two possible exceptions (Henkin \& Levy, 2002; Levy et al., 1999), there have been no studies investigating olfactory imagery in neuropsychological populations. If, as argued below, odor memory is crucial for routine olfactory perception, patients who have lost the ability to perceive odor quality through loss of olfactory memory (see Eichenbaum, Morton, Potter, \& Corkin, 1983) should also be unable to form olfactory images. In contrast, patients who have acquired anosmia through severing of the olfactory bulb and who are totally unable to smell should still evidence normal olfactory imagery, and preliminary evidence suggests they can (Levy et al., 1999). Studies of the latter type have been instrumental in advancing understanding of visual imagery (see, e.g., Farah, 2000).

A further question that remains unaddressed concerns the functional value of olfactory imagery. We have argued elsewhere (Stevenson \& Boakes, 2003) that olfactory volitional imagery might in fact be detrimental. As Finke (1980) has noted, imagery typically activates only selective parts of the multilevel visual information processing hierarchy, which may allow a person to readily discriminate between internally and externally generated percepts. The information-processing hierarchy in olfaction is arguably much flatter; consequently, activating one part of this hierarchy likely has a proportionally greater chance of producing a sensation akin to that normally encountered when smelling something. Such confusions could have incurred a fatal evolutionary penaltydid I sense the presence of a predator, or did I imagine it? Alternatively, olfactory imagery may be crucial to routine odor perception, and especially to identification. Rabin (1988) observed that learning to name a set of unfamiliar odors improved participants' ability to discrim- 
inate them from each other more than did mere exposure. This finding may imply that initial odor identification leads to a "sharpening" of the olfactory percept via the activation of a more specific odor memory - an image. Finally, olfactory imagery may be far more developed in experts, such as perfumers, flavorists, and chefs than in the general population. Apart from Gilbert et al. (1998), there has been no systematic investigation of olfactory imagery in such groups.

So far, we have remained silent about the processes that might underpin olfactory imagery. Before offering our perspective on this problem, it will be instructive to examine how information processing normally occurs when an odorant is sniffed: The chemical stimulus is transduced by receptors located on the olfactory mucosa in the nasal cavity. This produces a complex temporal and spatial pattern of activation across the glomeruli in the olfactory bulb (Buck, 2000). This pattern is then matched to existing patterns in odor memory, and a representation is generated according to the degree to which the pattern matches existing encodings in this store $(\mathrm{Li}$ \& Hertz, 2000). A fairly convincing case can be made for this train of events on the basis of neurophysiological, neuropsychological, and learning-based studies (see Eichenbaum et al., 1983; Haberly, 2001; Haberly \& Bower, 1989; Hasselmo, Anderson, \& Bower, 1992; Hudson, 1999; Stevenson \& Boakes, 2003; Wilson \& Stevenson, 2003).

How, then, is the resulting percept identified? Presumably this process relies upon the formation/existence of associative links between the perceptual representation and information stored in semantic memory. Some evidence for this assertion is provided by modality-specific anomia, in which a participant is able to identify odors by pointing to their pictures but unable to produce their names, whereas the participant can name auditory and tactile stimuli significantly better (Goodglass, Barton, \& Kaplan, 1968). Further evidence for this type of account is apparent in the many studies that have examined the acquisition of odor names through paired-associate learning (e.g., Davis, 1975, 1977). These studies have relied upon the ability of participants to acquire associations between perceptual (odor representation) and semantic information (a name). Acquisition of such associations is typically inferior to that of comparable visual stimuli (Davis, 1975, 1977), and this fact almost certainly relates to the finding that odor naming itself is poor relative to naming in other modalities (Herz \& Engen, 1996). This is evidenced by the difficulty that participants have in identifying even the most common odors in the absence of appropriate contextual cues (Cain, 1979; Desor \& Beauchamp, 1974; Larsson, 1997; Lawless \& Engen, 1977). Although some of this failure may be attributed to perceptual confusion (see Jonsson \& Olsson, 2003), Cain et al. (1998) concluded that "unstable access to semantic information presumably largely governs performance at identification" (p. 320).

Further support for this perspective is provided by recent research on the "tip of the nose" (TON) phenome- non, in which participants feel they know an odor's name but are unable to generate it (Lawless \& Engen, 1977). Unlike the analogous situation of "tip of the tongue," far fewer TON states are positively resolved, and participants appear to have little access to semantic information about the TON odor (Jonsson \& Olsson, 2003). All of these findings suggest a quantitatively and qualitatively different relationship between language and olfaction than between language and other modalities.

If links from an odor's perceptual representation to its name are weak, it seems plausible that the reverse is also true, that links from the name to the odor's representation are also weak. In this case, just as it is hard to evoke an odor's name, the same may apply to evoking its perceptual representation when presented with its name. Thus in the "typical" odor imagery experiment, participants are asked to form an olfactory image when presented with a word such as "banana." In the same way that banana odor may be hard to name, the perceptual representation of banana may also be difficult to evoke. Some evidence consistent with this account was recently obtained by Stevenson and Case (2005), who observed that those reporting themselves as better at olfactory imagery were better at identifying odors. Although this study was the first attempt to test that notion, the finding could potentially explain why many participants report that they have either never or only rarely formed an odor image (Lawless, 1997). In other words, evocation may be more difficult in the olfactory system because of the tenuous connections between names and olfactory representations. Thus, odor imagery may be judged to be poor relative to the other senses not because of any inherent difference in the capacity to experience imagery but because of difficulty in evocation, a consequence of the impoverished link between olfaction and language.

One implication of this account is that paired-associate learning between an odor and a name, or between an odor and some other cue, should subsequently improve the ability to evoke the odor's image. It is interesting to speculate whether the relative success of the psychophysical performance imagery studies, many of which were reliant upon initial paired-associate learning (colorodor), may have resulted from this cause. The same also applies to the more recent studies reported by Djordjevic et al. (Djordjevic, Zatorre, \& Jones-Gotman, 2004; Djordjevic, Zatorre, Petrides, \& Jones-Gotman, 2004), which also employed a pretraining phase in which the target odors and their names were presented. The message here appears to be that if participants learn to name the odors later used in the imagery phase, imagery performance may be markedly improved through better evocation of the odor's image.

A directly related issue concerns attempts to measure the association between phenomenal imagery ability and performance on an experimental task. The assumption in such research is that equipotentiality exists between stimuli-that is, how good you are at imagining one stimulus predicts how good you are at imagining another. However, if image generation is causally related 
to the ability to name particular odors, as the associative account suggests, this assumption is likely to be incorrect. This is best illustrated by example: In an experiment in which participants are asked to imagine lemon and can do so, asking them on a self-report questionnaire whether they can imagine several other odors, but not lemon, may be relatively uninformative about their performance on that particular experimental task. If idiosyncratic differences in odor naming ability do dictate the ease with which images may be evoked, then individual differences in odor imagery ability may really be differences in naming ability.

An alternative to this associative account of difficulty of evocation is that routine olfaction actively interferes with language processing, and vice versa, as both rely upon a common information-processing pathway based on the temporally dynamic character of spoken language and smell (Lorig, 1999). An advantageous aspect of this theory is that it avoids the potentially dubious anatomical reasoning that the relationship between language and olfaction is weak because of (1) the physical separation of the primary olfactory cortex from language processing areas and (2) attenuated neural links between these sites - the usual reasons given for poor odor naming. From Lorig's perspective, however, verbal instructions to imagine a smell can be viewed as interfering with the generation of an olfactory image. It should be possible to contrast the associative approach described above directly with this interference account, as training to name an odor should improve the ability of a participant to imagine that odor (when verbally cued), but training should have no effect on the ability of a verbal cue to create interference.

To experience an image requires the retention of an evoked perceptual memory for a brief period of time. That is, the process relies upon some form of short-term store. Evidence favoring a dissociable short-term store in olfaction has been reviewed by T. L. White (1998), but it is not compelling. There are no clear neuropsychological dissociations between long- and short-term stores, there are no obvious coding differences between putative long- and short-term memory tasks, and evidence suggestive of capacity differences is contaminated by disparities in set similarity (Stevenson \& Boakes, 2003). We have argued elsewhere that there is in fact no need for dissociable memory systems in olfaction and that all of the current evidence can be accommodated within a singlememory system that allows for initial activation and then slow decay, most of which occurs outside of conscious awareness (see Cowan, 1988). The implications of this account for olfactory imagery are that top-down activation yields conscious perception of an olfactory memory - an image - and that its initial slow decay represents the short-term memory component. In sum, the essentials of this account are that the same processes used in perception become active during imagery - in essence the very same type of model that has found wide currency in the visual imagery literature (cf. Finke, 1980; Kosslyn \& Thompson, 2003).
A final issue is the extent to which this account can explain nonvolitional imagery. The simplest case is that of homomodal cued images, such as those that occur when an odor acquires a new quality. We have argued elsewhere that these interactions between stimulus-driven percept and memory-based image derive directly from the pattern-matching process described earlier (Stevenson \& Boakes, 2003). That is, when a participant experiences an odor mixture, its representation is stored and subsequently reactivated by the presence of similar subcomponents - reintegration. What is then experienced is in fact an automatic memory-based image. To extend this account to cover heteromodal cues requires a further assumption-namely, that associations also exist between an odor's perceptual representation and visual cues such as color. Although this is not a perilous assumption, it has two implications that are more contentious: The first relates to the finding that color effects are often generic, suggesting that color may activate many olfactory representations, if we assume its effects are perceptually based. The second follows on from this idea: If color can do this, could words? That is, could another source of variance in many imagery experiments be that when asked to imagine lemon, participants' attempts at evoking a specific lemon odor image are not only difficult for the reasons described above but also face an extra obstacle - namely, that some participants imagine a generic citrus smell? The key for understanding heteromodal cues and how they may work is perhaps to understand whether they do have a perceptual basis. If heteromodal cues are semantically based, this may explain the abundance of experimental findings. If they are perceptually based, then this abundance could reflect overlearning of color-odor associations.

Two further instances of nonvolitional imagery are dreams and hallucinations. Olfactory dreams may rely for their evocation upon connections from semantic or visual memory, the former being suggested by the correlation between having recalled an olfactory dream and better odor naming (Stevenson \& Case, 2005). That olfactory dream images are themselves evoked by other cues is suggested by their rarity and, more intriguingly, by the absence of "creativity" in olfactory dreams. A though visual dreams commonly involve bizarre juxtaposition of images, our study of olfactory dreams (Stevenson $\&$ Case, 2005) revealed their ordinariness and contextual appropriateness - no petrol-scented bacon or rose-smelling bricks.

The most problematic issue, though, is that of olfactory hallucinations. Because their cause is likely to depend upon the medical condition that produces them, we refrain here from suggesting any general mechanism. However, one thing is clear: OHs appear capable of generating an affective response superior to that produced by volitional images, because $\mathrm{OHs}$ are often accompanied by spontaneous reports of negative affect. If this distinction holds, it may suggest that affectless volitional images may be necessary so that they are not confused with externally generated, affect-laden olfactory sensations. 


\section{CONCLUSION}

Much of the uncertainty surrounding olfactory imagery may result from the difficulty that participants have in evoking odor images. This can lead participants to use nonimaginal strategies in putative odor imagery tasks, resulting in a misleading general conclusion that odor imagery does not exist. The breadth of evidence reviewed here suggests contrary conclusions: that olfactory imagery can occur, that olfactory information processing can support it, and that difficulty of evocation results directly from the well-documented finding that language and olfaction are poorly interconnected. In sum, if language is bypassed (by training, for example), the capacity to form olfactory images is likely as good as the capacity to form images using any other modality.

\section{REFERENCES}

Acharya, V., Acharya, J., \& Luders, H. (1998). Olfactory epileptic auras. Neurology, 51, 56-61.

Algom, D., \& CAIN, W. S. (1991). Remembered odors and mental mixtures: Tapping reservoirs of olfactory knowledge. Journal of Experimental Psychology: Human Perception \& Performance, 17, 1104-1119.

Algom, D., Marks, L. E., \& CaIn, W. S. (1993). Memory psychophysics for chemosensation: Perceptual and mental mixtures of odor and taste. Chemical Senses, 18, 151-160.

Allen, I. M. (1944). Spontaneous olfactory and gustatory phenomena with and without organic lesions of the brain. New Zealand Medical Journal, 43, 165-168.

Alroe, C. J., \& McIntyre, J. N. M. (1983). Visual hallucinations: The Charles Bonnet syndrome and bereavement. Medical Journal of Australia, 2, 674-675.

Andrade, C., SRInath, S., \& Andrade, C. (1989). True hallucinations in non-psychotic states. Canadian Journal of Psychiatry, 34, 704-706.

ANDY, O. J. (1967). The amygdala and hippocampus in olfactory aura. Electroencephalography \& Clinical Neurophysiology, 23, 292.

Ardila, A., \& Sanchez, E. (1988). Neuropsychologic symptoms in the migraine syndrome. Cephalalgia, 8, 67-70.

Ashton, R., \& White, K. D. (1980). Sex differences in imagery vividness: An artefact of the test. British Journal of Psychology, 71, 35-38.

BADDEley, A. D., \& ANDradE, J. (2000). Working memory and the vividness of imagery. Journal of Experimental Psychology: General, 129, 126-145.

BAIRD, J. C., \& HARDER, K. A. (2000). The psychophysics of imagery. Perception \& Psychophysics, 62, 113-126.

Barabasz, A. F., \& Gregson, R. A. M. (1979). Antarctic winteringover, suggestion and transient olfactory stimulation: EEG evoked potential and electrodermal responses. Biological Psychology, 9, 285-295.

Barodawala, S., \& Mulley, G. P. (1997). Visual hallucinations. Journal of the Royal College of Physicians of London, 31, 42-48.

BARRETT, T. R., \& CAYLOR, M. R. (1998). Verbal hallucinations in normals: V. Perceived reality characteristics. Personality \& Individual Differences, 25, 209-221.

Bensafi, M., Porter, J., Pouliot, S., Mainland, J., Johnson, B., Zelano, C., Young, N., Bremner, E., Aframian, D., Khan, R., \& Sobel, N. (2003). Olfactomotor activity during imagery mimics that during perception. Nature Neuroscience, 6, 1142-1144.

BetTs, G. H. (1909). The distribution and functions of mental imagery (Contributions to Education Series, No. 26). New York: Teachers College, Columbia University.

Bowman, K. M., \& RaYmond, A. F. (1931). A statistical study of hallucinations in the manic-depressive psychoses. American Journal of Psychiatry, 11, 299-309.

BROMBERG, W., \& SCHILDER, P. (1934). Olfactory imagination and olfactory hallucinations. Archives of Neurology \& Psychiatry, 32, 467-492.

Brower, D. (1947). The experimental study of imagery: II. The rela- tive predominance of various imagery modalities. Journal of General Psychology, 37, 199-200.

BUCK, L. B. (2000). The molecular architecture of odor and pheromone sensing in mammals. Cell, 100, 175-187.

Bullen, F. J. (1899). Olfactory hallucinations in the insane. Journal of Mental Science, 45, 513-533.

Burstein, A. (1987). Olfactory hallucinations [Abstract]. Hospital \& Community Psychiatry, 38, 80.

CAIN, W. S. (1978). The odoriferous environment and the application of olfactory research. In E. C. Carterette \& M. P. Friedman (Eds.), Handbook of perception: Vol. 6A. Tasting and smelling (pp. 277299). New York: Academic Press.

CAIN, W. S. (1979). To know with the nose: Keys to odor identification. Science, 203, 467-470.

CAIN, W. S., \& AlgOM, D. (1997). Perceptual and mental mixtures in odor and in taste: Are there similarities and differences between experiments or between modalities? Reply to Schifferstein (1997). Journal of Experimental Psychology: Human Perception \& Performance, 23, 1588-1593.

Cain, W. S., De WiJK, R., Lulejian, C., Schiet, F., \& See, L.-C. (1998). Odor identification: Perceptual and semantic dimensions. Chemical Senses, 23, 309-326.

CALKINS, M. W. (1893). Statistics of dreams. American Journal of Psychology, 5, 311-343.

Carrasco, M., \& Ridout, J. B. (1993). Olfactory perception and olfactory imagery: A multidimensional analysis. Journal of Experimental Psychology: Human Perception \& Performance, 19, 287-301.

Case, T. I., Stevenson, R. J., \& Dempsey, R. A. (2004). Reduced discriminability following perceptual learning with odours. Perception, 33, 113-119.

CHITANONDH, H. (1966). Stereotaxic amygdalotomy in the treatment of olfactory seizures and psychiatric disorders with olfactory hallucination. Confinia Neurologica, 27, 181-196.

Clark, C. C., \& LAWLESS, H. T. (1994). Limiting response alternatives in time-intensity scaling: An examination of the halo dumping effect. Chemical Senses, 19, 583-594.

CowAN, N. (1988). Evolving conceptions of memory storage, selective attention, and their mutual constraints within the human information processing system. Psychological Bulletin, 104, 163-191.

Crosley, C. J., \& Dhamoon, S. (1983). Migrainous olfactory aura in a family. Archives of Neurology, 40, 459.

Crowder, R. G., \& Schab, F. R. (1995). Imagery for odors. In F. R. Schab \& R. G. Crowder (Eds.), Memory for odors (pp. 93-107). Mahwah, NJ: Erlbaum.

Cytowic, R. E. (2002). Synesthesia: A union of the senses. Cambridge, MA: MIT Press.

Dalton, P. (1996). Odor perception and beliefs about risk. Chemical Senses, 21, 447-458.

DALTON, P. (1999). Cognitive influences on health symptoms from acute chemical exposure. Health Psychology, 18, 579-590.

DALY, D. (1958). Uncinate fits. Neurology, 8, 250-260.

Davidson, G. M. (1938). Concerning hallucinations of smell. Psychiatric Quarterly, 12, 253-270.

DAvis, R. G. (1975). Acquisition of verbal associations to olfactory stimuli of varying familiarity and to abstract visual stimuli. Journal of Experimental Psychology: Human Learning \& Memory, 1, 134-142.

DAVIS, R. G. (1977). Acquisition and retention of verbal associations to olfactory and abstract visual stimuli of varying similarity. Journal of Experimental Psychology: Human Learning \& Memory, 3, 37-51.

DAVIS, R. G. (1981). The role of nonolfactory context cues in odor identification. Perception \& Psychophysics, 30, 83-89.

Desor, J. A., \& Beauchamp, G. K. (1974). The human capacity to transmit olfactory information. Perception \& Psychophysics, 16, 551-556.

Devanand, D. P., Miller, L., Richards, M., Marder, K., Bell, K., Mayeux, R., \& STERN, Y. (1992). The Columbia University scale for psychopathology in Alzheimer's disease. Archives of Neurology, 49, 371-376.

DEVINSKY, O., Khan, S., \& Alper, K. (1998). Olfactory reference syndrome in a patient with partial epilepsy. Neuropsychiatry, Neuropsychology, \& Behavioral Neurology, 11, 103-105. 
Diamond, S., Freitag, F. G., Prager, J., \& Gandi, S. (1985). Olfactory aura and migraine. New England Journal of Medicine, 312, 1390-1391.

Distel, H., \& Hudson, R. (2001). Judgement of odor intensity is influenced by subjects' knowledge of the odor source. $\underline{\text { Chemical Senses, }}$ 26, 247-251.

DJORDJEVIC, J., Zatorre, R., \& Jones-Gotman, M. (2004). Effects of perceived and imagined odors on taste detection. Chemical Senses, 29, 199-208.

Djordjevic, J., Zatorre, R., Petrides, M., \& Jones-Gotman, M. (2004). The mind's nose: Effects of odor and visual imagery on odor detection. Psychological Science, 15, 143-148.

Doty, R. L. (2001). Olfaction. Annual Review of Psychology, 52, 423-452.

DravNiEKs, A. (1985). Atlas of odor character profiles. Philadelphia: ASTM

Dubose, C. N., Cardello, A. V., \& Maller, O. (1980). Effects of colorants and flavorants on identification, perceived flavor intensity, and hedonic quality of fruit-flavored beverage and cake. Journal of Food Science, 45, 1393-1415.

EFRON, R. (1956). The effect of olfactory stimuli in arresting uncinate fits. Brain, 79, 267-281.

Eichenbaum, H., Morton, T. H., Potter, H., \& Corkin, S. (1983). Selective olfactory deficits in case H.M. Brain, 106, 459-472.

Ellenson, G. S. (1986). Disturbances of perception in adult female incest survivors. Journal of Contemporary Social Work, 67, 149-159.

Elmes, D. G. (1998). Is there an inner nose? Chemical Senses, 23, 443445.

Embril, J. A., Camfield, P., Artsob, H., \& Chase, D. P. (1983). Powassan virus encephalitis resembling herpes simplex encephalitis. Archives of Internal Medicine, 143, 341-343.

ENGEN, T. (1972). The effect of expectation on judgments of odor. Acta Psychologica, 36, 450-458.

ENGEN, T. (1982). The perception of odors. New York: Academic Press. Engen, T. (1991). Odor sensation and memory. New York: Praeger.

Eskenazi, B., Cain, W. S., Novelly, R. A., \& Friend, K. B. (1983). Olfactory functioning in temporal lobectomy patients. Neuropsychologia, 21, 365-374.

FARAH, M. J. (2000). The cognitive neuroscience of vision. Malden, MA: Blackwell.

FAris, A. A., \& Terrence, C. F. (1989). Limbic system symptomatology associated with colloid cyst of the third ventricle. Journal of Neurology, 236, 60-61.

FINKE, R. A. (1980). Levels of equivalence in imagery and perception. Psychological Review, 87, 113-132.

FINKE, R. A. (1985). Theories relating mental imagery to perception. Psychological Bulletin, 98, 236-259.

FischMAN, L. G. (1983). Dreams, hallucinogenic drug states, and schizophrenia: A psychological and biological comparison. Schizophrenia Bulletin, 9, 73-94.

FISHER, S. (1955). An investigation of alleged conditioning phenomena under hypnosis. Journal of Clinical \& Experimental Hypnosis, 3, 71103.

FoulKes, D., \& Vogel, G. (1965). Mental activity at sleep onset. Journal of Abnormal Psychology, 70, 231-243.

FrANK, R. A., \& BYRAM, J. (1988). Taste-smell interactions are tastant and odorant dependent. Chemical Senses, 13, 445-455.

Fuller, G. N., \& GuilofF, R. J. (1987). Migrainous olfactory hallucinations. Journal of Neurology, Neurosurgery, \& Psychiatry, 50, 1688-1690.

GiLbert, A. N., Crouch, M., \& Kemp, S. E. (1998). Olfactory and visual mental imagery. Journal of Mental Imagery, 22, 137-146.

Goodglass, H., Barton, M. I., \& KaPlan, E. F. (1968). Sensory modality and object-naming in aphasia. Journal of Speech \& Hearing Research, 11, 488-496.

GotTFried, J. A., \& Dolan, R. J. (2003). The nose smells what the eye sees: Crossmodal visual facilitation of human olfactory perception. Neuron, 39, 375-386.

GREENBERG, M. S. (1995). Olfactory hallucinations. In M. J. Serby \& K. L. Chobor (Eds.), Science of olfaction (pp. 467-499). New York: Springer.

HaberLy, L. B. (2001). Parallel-distributed processing in olfactory cor- tex: New insights from morphological and physiological analysis of neuronal circuitry. Chemical Senses, 26, 551-577.

Haberly, L. B., \& Bower, J. M. (1989). Olfactory cortex: Model circuit for study of associative memory? Trends in Neurosciences, 12, 258-264.

HAMILTON, A. M. (1882). On cortical sensory discharging lesions (sensory epilepsy). New York Journal of Medicine, 35, 575-584.

Hasselmo, M. E., Anderson, B. P., \& Bower, J. H. (1992). Cholinergic modulation of cortical associative memory function. Journal of Neurophysiology, 67, 1230-1246.

HAUSSER-HAUW, C., \& BANCAUD, J. (1987). Gustatory hallucinations in epileptic seizures. Brain, 110, 339-359.

HeNkIN, R. I., \& LEVY, L. M. (2002). Functional MRI of congenital hyposmia: Brain activation to odors and imagination of odors and tastes. Journal of Computer Assisted Tomography, 26, 39-61.

HERz, R. S. (2000). Verbal coding in olfactory versus nonolfactory cognition. Memory \& Cognition, 28, 957-964.

Herz, R. S., \& CLEF, J. V. (2001). The influence of verbal labeling on the perception of odors: Evidence for olfactory illusions? Perception, 30, 381-391.

HERZ, R. S., \& ENGEN, T. (1996). Odor memory: Review and analysis. Psychonomic Bulletin \& Review, 3, 300-313.

Hinton, P. B., \& Henley, T. B. (1993). Cognitive and affective components of stimuli produced in three modes. Bulletin of the Psychonomic Society, 31, 595-598.

Horowitz, M. J. (1975). Hallucinations: An information-processing approach. In R. K. Siegel (Ed.), Hallucinations: Behavior, experience, and theory (pp. 163-195). Toronto: Wiley.

Hudson, R. (1999). From molecule to mind: The role of experience in shaping olfactory function. Journal of Comparative Physiology A, 185, 297-304.

Hurovitz, C. S., Dunn, S., Domhoff, G. W., \& Fiss, H. (1999). The dreams of blind men and women: A replication and extension of previous findings. Dreaming, 9, 183-193.

Hyman, A. (1983). The influence of color on the taste perception of carbonated water preparations. Bulletin of the Psychonomic Society, 21, 145-148.

Intons-Peterson, M. J., \& McDaniel, M. A. (1991). Symmetries and asymmetries between imagery and perception. In C. Cornoldi \& M. A. McDaniel (Eds.), Imagery and cognition (pp. 47-76). New York: Springer-Verlag.

JACKSON, J. H., \& BeEvor, C. E. (1890). Case of tumour of the right temporosphenoidal lobe bearing on the localisation of the sense of smell and on the interpretation of a particular variety of epilepsy. Brain, 12, 346-357.

JACKSON, J. H., \& STEWART, P. (1899). Epileptic attacks with a warning of a crude sensation of smell and with the intellectual aura (dreamy state) in a patient who had symptoms pointing to gross organic disease of the right temporo-sphenoidal lobe. Brain, 22, 534-549.

Jehl, C., Royet, J. P., \& Holley, A. (1995). Odor discrimination and recognition memory as a function of familiarization. Perception \& Psychophysics, 57, 1002-1011.

Jonsson, F. U., \& OLSSON, M. J. (2003). Olfactory metacognition. Chemical Senses, 28, 651-658.

Kaufman, M. D., Lassiter, K. R. L., \& Shenoy, B. V. (1988). Paroxysmal unilateral dysosmia: A cured patient. Annals of Neurology, 24, 450-451.

KEREKOVIC, M. (1972). The relationship between objective disorders of smell and olfactory hallucinations. Acta Oto-Rhino-Laryngologica Belgica, 26, 518-523.

KERR, N. (1993). Mental imagery, dreams, and perception. In C. Cavallero \& D. Foulkes (Eds.), Dreaming as cognition (pp. 18-37). New York: Prentice Hall, Harvester Wheatsheaf.

KnapP, P. H. (1956). Sensory impressions in dreams. Psychoanalytic Quarterly, 25, 325-347.

KNASKo, S. C., GilberT, A. N., \& Sabini, J. (1990). Emotional state, physical well-being and performance in the presence of feigned ambient odor. Journal of Applied Social Psychology, 20, 1345-1357.

Kopala, L. C., Good, K. P., \& Honer, W. G. (1994). Olfactory hallucinations and olfactory identification ability in patients with schizo- 
phrenia and other psychiatric disorders. Schizophrenia Research, 12, 205-211.

Kosslyn, S. M., Ganis, G., \& Thompson, W. L. (2003). Mental imagery: Against the nihilistic hypothesis. Trends in Cognitive Sciences, 7, 109-111.

KossLYN, S. M., \& Thompson, W. L. (2003). When is early visual cortex activated during visual mental imagery? Psychological Bulletin, 129, 723-746.

Kwapil, T. R., Chapman, J. P., Chapman, L. J., \& Miller, M. B. (1996). Deviant olfactory experiences as indicators of risk for psychosis. Schizophrenia Bulletin, 22, 371-382.

LARSSON, M. (1997). Semantic factors in episodic recognition of common odors in early and late childhood: A review. Chemical Senses, 22, 623-633.

LAWLESS, H. T. (1996). Flavor. In M. P. Friedman \& E. C. Carterette (Eds.), Handbook of perception and cognition: Vol. 16. Cognitive ecology (pp. 325-380). San Diego: Academic Press.

LAWLESS, H. T. (1997). Olfactory psychophysics. In G. K. Beauchamp \& L. Bartoshuk (Eds.), Tasting and smelling (pp. 125-175). San Diego: Academic Press.

LAWLESS, H. T., \& ENGEN, T. (1977). Associations to odors: Interference, mnemonics, and verbal labeling. Journal of Experimental Psychology: Human Learning \& Memory, 3, 52-59.

LEANING, F. E. (1925). An introductory study of hypnagogic phenomena. Proceedings of the Society for Psychical Research, 35, 287-411.

Lennox, W. G., \& Совв, S. (1935). Epilepsy XIII. Aura in epilepsy: A statistical review of 1359 cases. Archives of Neurology \& Psychiatry, 30, 374-387.

LeVy, L. M., Henkin, R. I., Lin, C. S., Hutter, A., \& Schellinger, D. (1999). Odor memory induces brain activation as measured by functional MRI. Journal of Computer Assisted Tomography, 23, 487-498.

LI, Z., \& HerTZ, J. (2000). Odour recognition and segmentation by a model olfactory bulb and cortex. Network: Computational Neural Systems, 11, 83-102.

LiNDAUER, M. S. (1969). Imagery and sensory modality. Perceptual \& Motor Skills, 29, 203-215.

LORIG, T. S. (1999). On the similarity of odor and language perception. Neuroscience \& Biobehavioral Reviews, 23, 391-398.

LORIG, T. S., \& RoBERTS, M. (1990). Odor and cognitive alteration of the contingent negative variation. Chemical Senses, 15, 537-545.

LYMAN, B. J. (1988). A mind's nose makes scents: Evidence for the existence of olfactory imagery (Doctoral dissertation, University of Notre Dame, 1987). Dissertation Abstracts International, 48, 2807B.

LyMAN, B. J., \& McDANiEL, M. A. (1990). Memory for odors and odor names: Modalities of elaboration and imagery. Journal of Experimental Psychology: Learning, Memory, \& Cognition, 16, 656-664.

MARKs, D. F. (1973). Visual imagery differences in the recall of pictures. British Journal of Psychology, 64, 17-24.

MARKs, L. E. (1978). The unity of the senses. New York: Academic Press.

Marsella, A. J., \& QuiJano, W. Y. (1974). A comparison of vividness of mental imagery across different sensory modalities in Filipinos and Caucasian-Americans. Journal of Cross-Cultural Psychology, 5, 451-465.

McDermott, K. B., \& Roediger, H. L., III (1994). Effects of imagery on perceptual implicit memory tests. Journal of Experimental Psychology: Learning, Memory, \& Cognition, 20, 1379-1390.

MCKellar, P., \& SimpSON, L. (1954). Between wakefulness and sleep: Hypnagogic imagery. British Journal of Psychology, 45, 266-276.

McKelvie, S. J. (1995). The VVIQ as a psychometric test of individual differences in visual imagery vividness: A critical quantitative review and plea for direction. Journal of Mental Imagery, 19, 1-106.

McLaughlin, S., \& Margolskee, R. F. (1994). The sense of taste: The internal molecular workings of the taste bud help it distinguish the bitter from the sweet. American Scientist, 82, 538-545.

Mizobuchi, M., Ito, N., TanaKa, C., SaKo, K., Sumi, Y., \& Sasaki, T. (1999). Unidirectional olfactory hallucination associated with ipsilateral unruptured intracranial aneurysm. Epilepsia, 40, 516-519.

Mohr, C., Hubener, F., \& LASKA, M. (2002). Deviant olfactory experiences, magical ideation, and olfactory sensitivity: A study with healthy German and Japanese subjects. Psychiatry Research, 111, 21-33.
Morrot, G., Brochet, F., \& Dubourdieu, D. (2001). The color of odors. Brain \& Language, 79, 309-320.

Moskowitz, H. R. (1979). Mind, body and pleasure: An analysis of factors which influence sensory hedonics. In J. H. A. Kroeze (Ed.), Preference behaviour and chemoreception (pp. 131-144). London: Information Retrieval.

Mueser, K. T., Bellack, A. S., \& Brady, E. U. (1990). Hallucinations in schizophrenia. Acta Psychiatrica Scandinavica, 82, 26-29.

Mulder, D. W., \& DALY, D. (1952). Psychiatric symptoms associated with lesions of temporal lobe. Journal of the American Medical Association, 150, 173-176.

NASHOLD, B. S., \& Wilson, W. P. (1969). Olfactory hallucinations evoked from stimulation of human thalamus. Confinia Neurologica, 32, 298-306.

Nesse, R. M., Carli, T., Curtis, G. C., \& Kleinman, P. D. (1983). Pseudohallucinations in cancer chemotherapy patients. American Journal of Psychiatry, 140, 483-485.

OHAYON, M. M. (2000). Prevalence of hallucinations and their pathological associations in the general population. Psychiatry Research, 97, 153-164.

O' MAHONEY, M. (1978). Smell illusions and suggestion: Reports of smells contingent on tones played on television and radio. Chemical Senses \& Flavor, 3, 183-189.

OsaKa, N. (1987). Memory psychophysics for pyridine smell scale. Bulletin of the Psychonomic Society, 25, 56-57.

Penfield, W., \& JASPER, H. (1954). Epilepsy and the functional anatomy of the human brain. Boston: Little, Brown.

Penfield, W., \& Perot, P. (1963). The brain's record of auditory and visual experience. Brain, 86, 595-696.

Perky, C. W. (1910). An experimental study of imagination. American Journal of Psychology, 21, 422-452.

PIERCE, J., \& HALPERN, B. (1996). Orthonasal and retronasal odorant identification based upon vapor phase input from common substances. Chemical Senses, 21, 529-543.

Potolicchio, S. J., JR., Lossing, J. H., O’Doherty, D. S., \& Henkin, R. I. (1986). Partial seizures with simple psychosensory symptomatology (cyclic phantosmia): A new and distinct seizure disorder [Abstract]. Clinical Research, 34, 635A.

Prescott, J., \& Stevenson, R. J. (1995). The effects of oral chemical irritation on tastes and flavors in frequent and infrequent users of chili. Physiology \& Behavior, 58, 1117-1127.

PRYSE-PHILliPS, W. (1971). An olfactory reference syndrome. Acta Psychiatrica Scandinavica, 47, 484-509.

PrYSE-PHILliPS, W. (1975). Disturbance in the sense of smell in psychiatric patients. Proceedings of the Royal Society of Medicine, $\mathbf{6 8}$, 472-474.

RABIN, M. D. (1988). Experience facilitates olfactory quality discrimination. Perception \& Psychophysics, 44, 532-540.

RANKIN, K. M., \& MARKS, L. E. (2000). Chemosensory context effects: Role of perceived similarity and neural commonality. Chemical Senses, 25, 747-759.

Rosman, P. N. (1974). Case 28-1974. New England Journal of Medicine, 291, 141-149.

Rouby, C., \& Bensafi, M. (2002). Is there a hedonic dimension to odors? In C. Rouby, B. Schaal, D. Dubois, R. Gervais, \& A. Holley (Eds.), Olfaction, taste and cognition (pp. 140-159). Cambridge: Cambridge University Press.

Royet, J. P., Hudry, J., Zald, D. H., Godinot, D., Gregoire, M. C., Lavenne, F., Costes, N., \& Holley, A. (2001). Functional neuroanatomy of different olfactory judgments. NeuroImage, 13, 506-519.

Rubert, S. L., Hollender, M. H., \& Mehrhof, E. G. (1961). Olfactory hallucinations. Archives of General Psychiatry, 5, 313-318.

SANDYK, R. (1981). Olfactory hallucinations in Parkinson's disease [Letter to the editor]. South African Medical Journal, 60, 950.

ScHAB, F. R. (1990). Odors and remembrance of things past. Journal of Experimental Psychology: Learning, Memory, \& Cognition, 16, 648655.

Schacter, D. (1976). The hypnagogic state: A critical review of the literature. Psychological Bulletin, 83, 452-481.

SchiffersteIn, H. P. (1997). Perceptual and imaginary mixtures in chemosensation. Journal of Experimental Psychology: Human Perception \& Performance, 23, 278-288. 
SchiffMan, S. S. (1974). Physicochemical correlates of olfactory quality. Science, $\mathbf{1 8 5}, 112-117$.

SchiffMAN, S. S., RobINSON, D. E., \& ERICKSON, R. P. (1977). Multidimensional scaling of odorants: Examination of psychological and physicochemical dimensions. Chemical Senses \& Flavor, 2, 375-390.

Scully, R. E., Galdabini, J. J., \& McNeely, B. U. (1979). Case records of the Massachusetts General Hospital. Weekly clinicopathological exercises. Case 44-1979. New England Journal of Medicine, 301, 987-994.

SEGAL, S. J., \& FusElla, V. (1971). Effect of images in six sense modalities on detection of visual signal from noise. Psychonomic Science, 24, 55-56.

Seydell, E. M. (1932). Olfactory disturbances. Journal of the American Medical Association, 99, 627-633.

SHEEHAN, P. W. (1967). A shortened form of Betts' Questionnaire upon mental imagery. Journal of Clinical Psychology, 23, 386-389.

SHEPARD, R. N. (1975). Form, formation, and transformation of internal representations. In R. L. Solso (Ed.), Information processing and cognition: The Loyola symposium (pp. 87-122). Hillsdale, NJ: Erlbaum.

SIEgEL, R. K. (1978). Cocaine hallucinations. American Journal of Psychiatry, 135, 309-314.

SLOSSON, E. E. (1899). A lecture experiment in hallucinations. Psychological Review, 6, 407-408.

SMITH, J. D. (1992). The auditory hallucinations of schizophrenia. In D. Reisberg (Ed.), Auditory imagery (pp. 151-178). Hillsdale, NJ: Erlbaum.

Smutzer, G. S., Trojanowski, J. Q., Lee, V. M.-Y., \& Arnold, S. E. (1998). Human olfactory mucosa in schizophrenia. Annals of OtoRhino-Laryngology, 107, 349-355.

SNYDER, F. (1970). The phenomenology of dreaming. In L. Madow and L. H. Snow (Eds.), The psychodynamic implications of the physiological studies of dreams (pp. 124-151). Springfield, IL: Thomas.

Sobel, N., Prabhakaran, V., Zhao, Z., Desmond, J. E., Glover, G. H., Sullivan, E. V., \& Gabrieli, J. D. E. (2000). Time course of odorantinduced activation in the human primary olfactory cortex. Journal of Neurophysiology, 83, 537-551.

Stedman, T. J., \& ClaIR, A. L. (1998). Neuropsychological, neurological and symptom correlates of impaired olfactory identification in schizophrenia. Schizophrenia Research, 32, 23-30.

Stevens, J. R. (1957). The "march" of temporal lobe epilepsy. A.M.A. Archives of Neurology \& Psychiatry, 77, 227-236.

STEVENSON, R. J. (2001a). The acquisition of odour qualities. Quarterly Journal of Experimental Psychology, 54A, 561-577.

Stevenson, R. J. (2001b). Associative learning and odor quality perception: How sniffing an odor mixture can alter the smell of its parts. Learning \& Motivation, 32, 154-177.

STEVENSON, R. J. (2001c). Perceptual learning with odors: Implications for psychological accounts of odor quality perception. Psychonomic Bulletin \& Review, 8, 708-712.

STEVENSON, R. J., \& BOAKES, R. A. (2003). A mnemonic theory of odor perception. Psychological Review, 110, 340-364.

Stevenson, R. J., \& BoAKes, R. A. (2004). Sweet and sour smells: Learned synesthesia between the senses of taste and smell. In G. A. Calvert, C. Spence, \& B. E. Stein (Eds.), The handbook of multisensory processes (pp. 69-83). Cambridge, MA: MIT Press.

Stevenson, R. J., Bonkes, R. A., \& Prescott, J. (1998). Changes in odor sweetness resulting from implicit learning of a simultaneous odor-sweetness association: An example of learned synesthesia. Learning \& Motivation, 29, 113-132.

Stevenson, R. J., Boakes, R. A., \& Wilson, J. P. (2000a). Counterconditioning following human odor-taste and color-taste learning. Learning \& Motivation, 31, 114-127.

SteVEnson, R. J., BoAKes, R. A., \& WILson, J. P. (2000b). Resistance to extinction of conditioned odor perceptions: Evaluative conditioning is not unique. Journal of Experimental Psychology: Learning, Memory, \& Cognition, 26, 423-440.
Stevenson, R. J., \& Case, T. I. (2005). Olfactory dreams: Phenomenology, relationship to volitional imagery and odor identification. Imagination, Cognition \& Personality, 24, 69-90.

Stevenson, R. J., Case, T. I., \& Boakes, R. A. (2003). Smelling what was there: Acquired olfactory percepts are resistant to further modification. Learning \& Motivation, 34, 185-202.

Stevenson, R. J., \& Prescott, J. (1997). Judgments of chemosensory mixtures in memory. Acta Psychologica, 95, 195-214.

Stevenson, R. J., Prescott, J., \& Boakes, R. A. (1995). The acquisition of taste properties by odors. Learning \& Motivation, 26, 433455.

Toone, B. K. (1978). Psychomotor seizures, arterio-venous malformation and the olfactory reference syndrome. Acta Psychiatrica Scandinavica, 58, 61-66.

TuOrila, H., CARDEllo, A. V., \& Lesher, L. L. (1994). Antecedents and consequences of expectations related to fat-free and regular-fat foods. Appetite, 23, 247-263.

VAN BurEn, J. M. (1961). Sensory, motor and autonomic effects of mesial temporal stimulation in man. Journal of Neurosurgery, 18, 273-288.

VAN DER KLAAUW, N. J., \& FranK, R. A. (1996). Scaling component intensities of complex stimuli: The influence of response alternatives. Environment International, 22, 21-31.

WeED, S. C., \& Hallam, F. M. (1896). Minor studies from the psychological laboratory of Wellesley college. American Journal of Psychology, 7, 405-411.

WeIL, A. A. (1955). Depressive reactions associated with temporal lobe-uncinate seizures. Journal of Nervous \& Mental Diseases, 121, 505-510.

WEISS, A. P., \& Heckers, S. (1999). Neuroimaging of hallucinations: A review of the literature. Psychiatry Research, 92, 61-74.

WeLLS, C. E. C. (1971). Central disorders of the special senses in the elderly. Gerontologica Clinica, 13, 329-338.

West, S. E., \& Doty, R. L. (1995). Influence of epilepsy and temporal lobe resection on olfactory function. Epilepsia, 36, 531-542.

White, K. D., Ashton, R., \& Law, H. (1978). The measurement of imagery vividness: Effects of format and order on Betts' Questionnaire upon mental imagery. Canadian Journal of the Behavioral Sciences, 10, 68-78.

White, T. L. (1998). Olfactory memory: The long and the short of it. Chemical Senses, 23, 433-441.

WhitTle, I. R., Allsop, J. L., \& HAlmagyi, G. M. (1985). Focal seizures: An unusual presentation of giant intracranial aneurysms. Surgical Neurology, 44, 533-540.

Wilson, D. A., \& Stevenson, R. J. (2003). The fundamental role of memory in olfactory perception. Trends in Neurosciences, 26, 243247.

Wolberg, F. L., \& Ziegler, D. K. (1982). Olfactory hallucination in migraine [Abstract]. Archives of Neurology, 39, 382.

Zadra, A. L., Nielsen, T. A., \& Donderi, D. C. (1998). Prevalence of auditory, olfactory, and gustatory experiences in home dreams. Perceptual \& Motor Skills, 87, 819-826.

ZeLlner, D. A., BARTOLI, A. M., \& ECKARD, R. (1991). Influence of color on odor identification and liking ratings. American Journal of Psychology, 104, 547-561.

ZeLlNER, D. A., \& KaUTZ, M. A. (1990). Color affects perceived odor intensity. Journal of Experimental Psychology: Human Perception \& Performance, 16,391-397.

\section{NOTE}

1. Thanks are due one of the reviewers for pointing out these literary allusions.

(Manuscript received January 15, 2004; revision accepted for publication August 10, 2004.) 